\title{
The Reduced Kinetic Description of Lean Premixed Combustion
}

\author{
A. L. SÁNCHEZ* \\ Area de Mecánica de Fluidos, Departamento de Ingeniería Mecánica, Universidad Carlos III de Madrid, \\ 28911 Leganés, Spain
}

\author{
A. LÉPINETTE, M. BOLLIG, and A. LIÑÁN \\ Departamento de Motopropulsión y Termofluidodinámica, E. T. S. I. Aeronáuticos, Universidad Politécnica de \\ Madrid, 28040 Madrid, Spain
}

and

B. LÁZARO

SENER, Severo Ochoa 4 (PTM), 28760 Tres Cantos, Spain

\begin{abstract}
Lean premixed methane-air flames are investigated in an effort to facilitate the numerical description of $\mathrm{CO}$ and NO emissions in LP (lean premixed) and LPP (lean premixed prevaporized) combustion systems. As an initial step, the detailed mechanism describing the fuel oxidation process is reduced to a four-step description that employs $\mathrm{CO}, \mathrm{H}_{2}$, and $\mathrm{OH}$ as intermediates not following a steady-state approximation. It is seen that, under conditions typical of gas-turbine combustion, this mechanism can be further simplified to give a two-step reduced description, in which fuel is consumed and $\mathrm{CO}$ is produced according to the fast overall step $\mathrm{CH}_{4}+$ $\frac{3}{2} \mathrm{O}_{2} \rightarrow \mathrm{CO}+2 \mathrm{H}_{2} \mathrm{O}$, while $\mathrm{CO}$ is slowly oxidized according to the overall step $\mathrm{CO}+\frac{1}{2} \mathrm{O}_{2} \rightarrow \mathrm{CO}_{2}$. Because of its associated fast rate, fuel consumption takes place in a thin layer where $\mathrm{CO}, \mathrm{H}_{2}$, and $\mathrm{OH}$ are all out of steady state, while $\mathrm{CO}$ oxidation occurs downstream in a distributed manner in a region where $\mathrm{CO}$ is the only intermediate not in steady state. In the proposed description, the rate of fuel consumption is assigned a heuristic Arrhenius dependence that adequately reproduces laminar burning velocities, whereas the rate of $\mathrm{CO}$ oxidation is extracted from the reduced chemistry analysis. Comparisons with results obtained with detailed chemistry indicate that the proposed kinetic description not only reproduces well the structure of one-dimensional unstrained and strained flames, including profiles of $\mathrm{CO}$, temperature, and radicals, but can also be used to calculate $\mathrm{NO}$ emissions by appending an appropriate one-step reduced chemistry description that includes both the thermal and the $\mathrm{N}_{2} \mathrm{O}$ production paths. Although methane is employed in the present study as a model fuel, the universal structure of the resulting $\mathrm{CO}$ oxidation region, independent of the fuel considered, enables the proposed formulation to be readily extended to other hydrocarbons.
\end{abstract}

\section{INTRODUCTION}

Pollutant emissions have become one of the limiting factors when designing combustion chambers of gas turbine engines. Among the different concepts designed to meet the ever more stringent regulations, lean premixed (LP) and lean premixed prevaporized (LPP) combustion systems are currently subject to intensive research. In general, traditional design methodologies, largely based on empirical correlations, fail to provide reliable predictions of $\mathrm{CO}$ and $\mathrm{NO}$ emissions. With the ever increasing computer power, the numerical computation of the associated reacting flow fields has become a commonly used design tool. For the numerical

*Corresponding author. E-mail: asanchez@ing.uc3m.es results to be meaningful, the computations must incorporate adequate models for the turbulent flow field, as well as an accurate representation for the underlying chemistry. The chemistry descriptions currently utilized to predict $\mathrm{CO}$ and NO emissions are based on empirically fitted rates, its applicability range therefore being necessarily limited.

A more reliable description can be obtained from systematically reducing the chemical kinetic mechanism, a technique that has been successfully utilized in the description of both premixed and diffusion flames [1-3]. This technique is applied in this paper to develop a reduced chemical-kinetic mechanism well suited for the description of combustion in LP and LPP systems. The conditions of interest here are then preheated fuel-lean mixtures 
burning at elevated pressures. Although a numerical study addressing combustion under those conditions has been published recently [4], experimental and numerical data of fuellean combustion at high temperature and pressure is very scarce. In particular, the range of conditions investigated here include lean and stoichiometric mixtures, pressures, $p$, larger than 5 bar and initial temperatures of the reactant mixture, $T_{u}$, above $500 \mathrm{~K}$. Because pollutant prediction is a major goal of the reduced mechanism, the needed description for fuel oxidation not only must accurately reproduce flame velocities and temperature distributions, but also concentrations of intermediates such as $\mathrm{CO}, \mathrm{O}, \mathrm{H}$, and $\mathrm{OH}$. In addition, oxides of nitrogen must be appropriately described by including in the mechanism all relevant production paths.

We shall show below that, under the conditions of interest, fuel oxidation to $\mathrm{H}_{2} \mathrm{O}$ and $\mathrm{CO}_{2}$ takes place in two global steps, namely, fast fuel consumption to produce $\mathrm{H}_{2} \mathrm{O}$ and $\mathrm{CO}$, and slow $\mathrm{CO}$ oxidation to give $\mathrm{CO}_{2}$. This is the so-called slow CO oxidation limit of premixed combustion [5], which has been used recently by Li et al. [6]. The two processes occur separately in the flow field. Thus, fuel is rapidly attacked by radicals in a relatively thin layer, where $\mathrm{CO}$ and $\mathrm{H}_{2} \mathrm{O}$ are produced. The fuel disappears in this layer and cannot penetrate downstream, while radicals are absent upstream, thereby freezing all chemical activity. Radicals and $\mathrm{H}_{2}$ maintain a steady state downstream from the fuel-consumption layer, in a large region where the $\mathrm{CO}$ produced in the fuel-consumption layer is slowly oxidized to give $\mathrm{CO}_{2}$. This slow oxidation process involves the simultaneous action of radical branching, radical recombination, and watergas shift reactions. Use of the steady-state condition for $\mathrm{H}_{2}$ and radicals enables the derivation of a simple expression for the $\mathrm{CO}$-oxidation rate in this region. It is also in this region where most of the NO production takes place. By appropriately reducing the corresponding kinetics, NO production is simplified to a single overall step. Therefore, through use of reduced-chemistry techniques a simple two-step description for the chemical activity in the CO-oxidation region is provided.

On the other hand, the fuel-consumption layer appears in the flow field as a thin surface that acts as a sink for fuel and radicals and as a source for carbon monoxide and water vapor. The rate at which fuel is consumed and $\mathrm{CO}$ is produced depends on the inner structure of this layer, in which radical branching, radical recombination, and fuel attack by radicals all take place simultaneously. This rate is of fundamental importance for the overall solution in that it determines the location of the fuel-consumption layer, therefore also affecting the solution in the much larger $\mathrm{CO}$ oxidation region. Because neither radicals nor $\mathrm{H}_{2}$ follows a steadystate approximation in this thin layer, the global rate of fuel conversion into $\mathrm{CO}$ cannot be easily extracted.

The existence of a thin fuel-consumption layer complicates the numerical description of gas-turbine combustion. Although the layer is very thin, and therefore only affects the solution through the rate at which fuel is converted into $\mathrm{CO}$, one needs in principle to resolve its inner structure to obtain as an outcome the required rate. This approach is not pursued in this paper, because the needed detailed description is anticipated to become prohibitely difficult in direct numerical simulations of three-dimensional (3D) unsteady flows. Instead, in the present development we choose to represent all of the chemical activity taking place in the fuel-consumption layer by a single overall step, whose rate is assigned a simple Arrhenius law. By fitting the rate parameters to reproduce laminar flame propagation velocities, it is expected that the proposed empirical law be able to reproduce the rate of fuel consumption (and, therefore, the location of the fuel-consumption layer) in complex flow configurations.

In summary, the reduced scheme proposed here comprises two global steps for fuel oxidation (fuel consumption and CO oxidation) and an additional step to describe NO production. Fuel consumption is fast, and takes place in a thin layer, while the other two reactions are much slower and take place downstream in a distributed manner. The proposed mechanism becomes inaccurate within the fuel-consumption layer, but the associated inaccuracies are seen to have a limited effect on the description of the overall solution. In particular, because the rates of $\mathrm{CO}$ oxidation and NO production 
are rationally derived by reducing the chemistry in the $\mathrm{CO}$-oxidation region, the mechanism can be anticipated to yield good predictions when used for the computation of pollutant emissions from combustion chambers.

A similar three-step description was employed in the unrelated work of Li et al. [6], but the resulting rate expressions are, however, different. On the one hand, for the application investigated in Ref. 6 fuel consumption was assumed to be controlled by turbulence, and was assigned a rate derived from a simple eddy-breakup model. Fuel consumption is assigned here an Arrhenius rate that, unlike that of Li et al. [6], enables calculations of laminar flames, serving also as starting point in turbulent modelling efforts. On the other hand, we found that some of the approximations used in Ref. 6 when deriving the CO-oxidation rate may lead to nonnegligible errors in the description of the postflame equilibrium solution. By retaining all these missing effects, our CO-oxidation rate is seen to describe accurately $\mathrm{CO}$ and radicals everywhere. In addition, only the thermal mechanism was considered in the NO production rate used in Ref. 6, which was applied to the calculation of NO emissions from a dual-fuel reciprocating engine. Although their simplified rate gave results in excellent agreement with experimental measurements for the application considered, we have found that the contribution of the nitrous-oxide path to NO emissions, that was previously neglected in Ref. 6 , is significant under LP and LPP combustion conditions, and is consequently retained here in the nitrogen chemistry.

The separate processes of fuel consumption and $\mathrm{CO}$ oxidation were also considered in the early work of Westbrook and Dryer [7]. Among other simplified descriptions, a two-step mechanism was proposed for the oxidation of hydrocarbon fuels. By selecting appropriately the reaction-rate parameters, the mechanism was able to accurately reproduce flame propagation velocities and adiabatic flame temperatures. However, the chemical structure of the flame itself could not be described with the proposed simplified description. More recent contributions of relevance are that of Swaminathan and Bilger [8], who performed direct numerical simulations of turbulent nonpremixed flames with a two-step mechanism [9] that employs the sum of $\mathrm{CO}$ and $\mathrm{H}_{2}$ as an intermediate, and the work Narayan and Rajan [10], who developed a simplified description for NO production in premixed methane-air flames that utilizes simple formulas for the evaluation of superequilibrium radical concentrations.

Although methane is selected as a model fuel in the present analysis, the results are applicable to other hydrocarbons because of the fuel-lean conditions addressed, that is, the resulting reduced mechanism is readily extendible by appropriately changing the fuel consumption rate as explained below. In the starting detailed chemistry description we choose to disregard the $C_{2}$ chain of fuel oxidation. This chain is known to be important in describing flame structures and burning velocities for sufficiently rich flames [3]. Because a considerable fraction of $\mathrm{CH}$ is created through a reaction path that begins with $\mathrm{C}_{2} \mathrm{H}_{2}+\mathrm{O} \rightarrow \mathrm{CH}_{2}+\mathrm{CO}$, retaining the $\mathrm{C}_{2}$ species can also be important in describing production of oxides of nitrogen through the so-called Fenimore mechanism, which involves $\mathrm{CH}+\mathrm{N}_{2} \rightarrow \mathrm{HCN}+\mathrm{N}$. Here, we are concerned with lean premixed environments, in which the Fenimore mechanism is seen to have only a marginal contribution to $\mathrm{NO}$ production. Therefore, in this study the $\mathrm{C}_{2}$ chain can be neglected altogether, yielding a detailed mechanism for fuel oxidation that contains 57 elementary reactions and 17 species. Details of the mechanism and its associated rates, which are largely taken from the recent recommendations of the CEC group [11], are presented in Appendix A. The nitrogen chemistry, which does not influence the fuel-oxidation process because of the very slow rates of its associated reactions, can be similarly simplified by retaining only the thermal and $\mathrm{N}_{2} \mathrm{O}$ paths of $\mathrm{NO}$ production, thereby limiting the necessary description to the 46 elementary steps with nine nitrogen-containing species shown in Appendix B.

Insight into the complex chemical processes may only be obtained by accounting for detailed chemistry and transport, a task that is nowadays feasible with reasonable effort in computations of one-dimensional (1D) laminar flames. Results corresponding to numerical computations of both freely propagating planar flames and strained flames stabilized in the counterflow 
configuration will be used here in the development and subsequent tests of the reduced chemistry description. The "FlameMaster" code [12] previously used, for instance, in Ref. 13, is utilized in the detailed calculations. Different values of the pressure, $p$, and of the temperature and equivalence ratio of the reactant mixture, $T_{u}$ and $\phi$, were considered in the computations, with conditions covering in particular those of aeronautical applications. The values of the elevated pressure and elevated temperature were computed by considering an isentropic compression of a given initial mixture. To represent cruise conditions, calculations were performed with $p=18 \mathrm{bar}, T_{u}=800 \mathrm{~K}$ and $\phi=$ 0.6 , with the values of $p$ and $T_{u}$ corresponding to a compression from standard atmospheric conditions at $11,000 \mathrm{~m}$. Similarly, sea-level values of temperature and pressure before the compressor were employed to calculate the case representative of takeoff conditions ( $p=40$ bar, $T_{u}=900 \mathrm{~K}$ and $\phi=0.6$ ).

As previously mentioned, although only $1 \mathrm{D}$ laminar flames will be computed in this paper, the proposed three-step mechanism is intended to ultimately serve in computations of gasturbine combustors. In such systems, turbulence dominates the transport of species and heat. Because molecular transport is secondary, nonunity Lewis number effects can be left out in computations. Consequently, a unity Lewis number can be assumed for all chemical species, an assumption that allows the derivation of simple transport equations for conserved scalars through linear combinations of the species and energy conservation equations, thereby reducing the number of differential equations to be integrated. Anticipating this type of development, the laminar computations with the reduced kinetics presented below incorporate a unity-Lewis-number assumption for all species. The general formulation in terms of conserved scalars corresponding to our three-step mechanism is presented as a separate section at the end of the paper. The resulting equations and boundary conditions can be used in direct numerical simulations (DNS) of complex, 3D, unsteady flows. They also serve as a basis for the derivation with modeling of the equations for describing combustion in turbulent flows (for instance, in large eddy simulations using pre- sumed probability density functions in the description of the subgrid fluctuations of main species and enthalpy).

The structure of the paper is as follows. First, a four-step mechanism for $\mathrm{CH}_{4}$ oxidation under lean premixed gas-turbine combustion conditions is derived. Further reduction to a two-step mechanism is presented next. The nitrogen chemistry is then addressed, and the starting chemistry description is reduced to two global reactions, which further simplify to a one-step mechanism by assuming $\mathrm{N}_{2} \mathrm{O}$ to follow a steadystate approximation. Validation of the reduced kinetics through extensive comparisons with detailed chemistry calculations of unstrained and strained planar flames is performed next. Finally, a general formulation for the energy and species conservation equations based on the reduced chemistry description is presented, and some concluding remarks, including the extension of the proposed model to other fuels, are given.

\section{THE FOUR-STEP REDUCED MECHANISM FOR $\mathrm{CH}_{4}$ OXIDATION}

Previous studies have shown that a four-step reduced description, including $\mathrm{CO}, \mathrm{H}_{2}$, and $\mathrm{H}$ as intermediate species out of steady state, suffices to describe most aspects of lean and stoichiometric premixed flames [3]. Numerical calculations incorporating such mechanisms accurately reproduce, for instance, laminar propagation velocities, with errors that are typically smaller than a few percent over a wide range of flow conditions. A three-step mechanism, that follows from introducing a steady-state assumption for $\mathrm{H}$ [1], and also a two-step mechanism, obtained by incorporating a partial-equilibrium approximation for the water-gas shift reaction $\mathrm{CO}+\mathrm{OH} \stackrel{17}{\rightleftharpoons} \mathrm{CO}_{2}+\mathrm{H}$, have also been proposed [9]. Although these reduced descriptions capture well the flame structure, they lead to fairly large errors in flame propagation velocities, so that a four-step mechanism is accepted as the minimal chemistry description for numerically computing premixed combustion.

The above considerations suggest that a fourstep mechanism is also an adequate first step in reducing the kinetic description of LP and LPP 

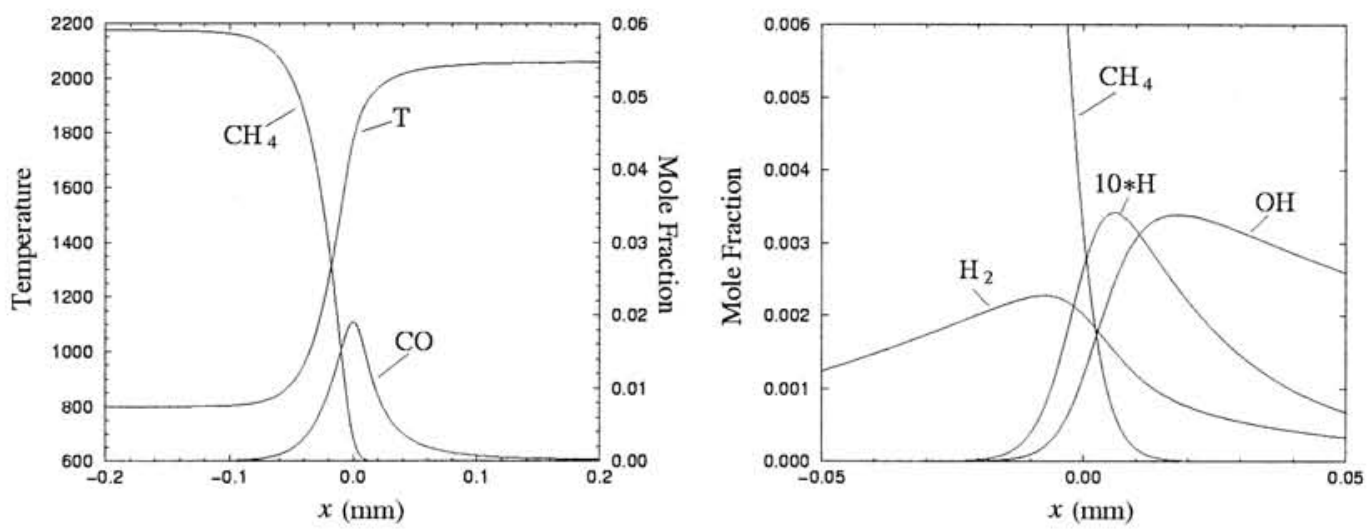

Fig. 1. Temperature and species mol fractions across a laminar methane-air flame with $p=18$ bar, $T_{u}=800 \mathrm{~K}$, and $\phi=$ 0.6 .

systems. Because of the particular characteristics of the combustion systems we study here, namely, preheated lean mixtures burning at relatively high pressures, modifications to the previous reduced kinetic mechanisms can be expected. To illustrate salient features of the resulting flames, profiles of species and temperature corresponding to an unstrained nonradiating premixed flame with $p=18 \mathrm{bar}, T_{u}=$ $800 \mathrm{~K}$, and $\phi=0.6$ are shown in Fig. 1. The computation, which was performed with the detailed chemistry description previously discussed, reveals, for instance, that the $\mathrm{OH}$ mol fraction is an order of magnitude larger than that of $\mathrm{H}$, suggesting that under fuel-lean conditions $\mathrm{OH}$ emerges as the dominant radical in the $\mathrm{H}_{2}-\mathrm{O}_{2}$ radical pool.

In selecting the intermediates out of steady state in the reduced description, one must choose either $\mathrm{O}, \mathrm{OH}$, or $\mathrm{H}$ as the radical representative of the $\mathrm{H}_{2}-\mathrm{O}_{2}$ radical pool. For lean mixtures, previous studies [3] have shown that the accuracy of the resulting mechanism is quite insensitive to this selection, while for rich mixtures $\mathrm{H}$ is the choice that provides most accurate results. In our study, two different four-step mechanisms were investigated in preliminary computations [14], namely, one using $\mathrm{CO}, \mathrm{H}_{2}$, and $\mathrm{H}$ out of steady state and one with $\mathrm{CO}, \mathrm{H}_{2}$, and $\mathrm{OH}$ out of steady state. Calculations of laminar unstrained and strained flames under conditions typical of gas-turbine combustion showed that both mechanisms provide equally accurate results. The analysis presented below will make use of the second mechanism, a choice that is motivated by the dominance of $\mathrm{OH}$ as the main component of the radical pool. Note that the results of the following section, in which all $\mathrm{H}_{2}-\mathrm{O}_{2}$ radicals and $\mathrm{H}_{2}$ are assumed to maintain steady state in the region where $\mathrm{CO}$ is oxidized, are however, independent of this selection.

Introducing steady-state approximations for all intermediates except $\mathrm{CO}, \mathrm{H}_{2}$, and $\mathrm{OH}$ yields the four-step reduced chemical-kinetic mechanism

$$
\begin{aligned}
& \mathrm{CH}_{4}+2 \mathrm{OH} \rightarrow \mathrm{CO}+\mathrm{H}_{2} \mathrm{O}+2 \mathrm{H}_{2}, \\
& \mathrm{H}_{2}+\mathrm{O}_{2} \rightleftharpoons 2 \mathrm{OH}, \\
& 2 \mathrm{OH}+\mathrm{H}_{2} \rightleftharpoons 2 \mathrm{H}_{2} \mathrm{O}, \\
& \mathrm{CO}+\mathrm{H}_{2} \mathrm{O} \rightleftharpoons \mathrm{CO}_{2}+\mathrm{H}_{2} .
\end{aligned}
$$

The mol fractions of all intermediates not present in the above global reactions are very small, and contribute negligibly to the overall mass balance. As can be seen, fuel consumption occurs according to step $\mathrm{I}^{\prime}$ in a process that involves radical removal. Step II' is the oxygenconsumption step, which produces radicals through the hydrogen-oxygen chain, and step III' represents radical recombination. The final step IV' is the water-gas shift that converts the $\mathrm{CO}$ produced by step I' to $\mathrm{CO}_{2}$.

Although several elementary reactions contribute to the rate of global steps $I^{\prime}-\mathrm{IV}^{\prime}$, retaining only a few contributors to each step is seen to provide a reasonably accurate description. If for instance an error of $10 \%$ is accepted in the 
calculation of laminar flame velocities for $p>5$ bar, $T_{u}>500 \mathrm{~K}$ and $\phi \leq 1$, then an appropriate set of simplified global rates (moles per unit volume per unit time) is found to be

$$
\begin{aligned}
& \omega_{\mathrm{I}^{\prime}}=k_{34 f}\left[\mathrm{CH}_{4}\right][\mathrm{H}]+k_{36 f}\left[\mathrm{CH}_{4}\right][\mathrm{OH}], \\
& \omega_{\mathrm{II}^{\prime}}=k_{1 f}\left[\mathrm{O}_{2}\right][\mathrm{H}]-k_{1 b}[\mathrm{O}][\mathrm{OH}], \\
& \omega_{\mathrm{III}^{\prime}}=k_{6 f}[\mathrm{M}]\left[\mathrm{O}_{2}\right][\mathrm{H}]-k_{6 b}[\mathrm{M}]\left[\mathrm{HO}_{2}\right], \\
& \omega_{\mathrm{IV}^{\prime}}=k_{17 f}[\mathrm{CO}][\mathrm{OH}]-k_{17 b}\left[\mathrm{CO}_{2}\right][\mathrm{H}],
\end{aligned}
$$

where $[i]$ denotes the concentration of chemical species $i, \mathrm{M}$ representing a third body, and $k_{j f}$ and $k_{j b}$ the specific reaction-rate constants in the forward and backward directions for the elementary reactions $\mathrm{CH}_{4}+\mathrm{H} \stackrel{34}{=} \mathrm{CH}_{3}+\mathrm{H}_{2}$, $\mathrm{CH}_{4}+\mathrm{OH} \stackrel{36}{=} \mathrm{CH}_{3}+\mathrm{H}_{2} \mathrm{O}, \mathrm{O}_{2}+\mathrm{H} \stackrel{1}{\rightleftharpoons} \mathrm{O}+$ $\mathrm{OH}, \mathrm{O}_{2}+\mathrm{H}+\mathrm{M} \stackrel{6}{\rightleftharpoons} \mathrm{HO}_{2}+\mathrm{M}$, and $\mathrm{CO}+\mathrm{OH}$ $\underline{17} \mathrm{CO}_{2}+\mathrm{H}$. Expressions for these reactionrate constants are given in Appendix $\mathrm{A}$. Note that, if the reverse rate of reaction 6 were not included in the mechanism, then the resulting equilibrium values of all intermediates for the reduced mechanism $I^{\prime}-I V^{\prime}$ would be zero, thereby potentially introducing significant errors in predictions of $\mathrm{CO}$ emissions. Also, because postflame NO production depends on the equilibrium radical level, this approximation of irreversible radical recombination would lead to underpredictions of NO formation. For these reasons, the backward rate of reaction 'III' is retained in the mechanism for increased accuracy.

Suitable simplified expressions for the concentrations of $\mathrm{H}$ and $\mathrm{O}$, necessary in evaluating Eq. 1, can be obtained by further assuming partial equilibrium of reactions $\mathrm{H}_{2}+\mathrm{OH} \stackrel{3}{\rightleftharpoons}$ $\mathrm{H}_{2} \mathrm{O}+\mathrm{H}$ and $\mathrm{OH}+\mathrm{OH} \stackrel{4}{\rightleftharpoons} \mathrm{H}_{2} \mathrm{O}+\mathrm{O}$ to give

$[\mathrm{H}]=K_{3}\left[\mathrm{H}_{2}\right][\mathrm{OH}] /\left[\mathrm{H}_{2} \mathrm{O}\right]$

and

$$
[\mathrm{O}]=K_{4}[\mathrm{OH}]^{2} /\left[\mathrm{H}_{2} \mathrm{O}\right] \text {, }
$$

where $K_{3}=k_{3 f} / k_{3 b}$ and $K_{4}=k_{4 f} / k_{4 b}$ are equilibrium constants. Equations 2 and 3 can also be obtained as severe truncations of the steady-state expressions for $\mathrm{H}$ and $\mathrm{O}$ in which only the elementary reactions 3 and 4 are assumed to contribute to the production and consumption of these species. The concentra- tion of hydroperoxyl radicals needed to evaluate the backward rate of III' can be obtained from the truncated steady-state expression

$$
\left[\mathrm{HO}_{2}\right]=\frac{k_{6 f}[\mathrm{M}]\left[\mathrm{O}_{2}\right][\mathrm{H}]+k_{11 b}\left[\mathrm{O}_{2}\right]\left[\mathrm{H}_{2} \mathrm{O}\right]}{k_{6 b}[\mathrm{M}]+k_{11 f}[\mathrm{OH}]},
$$

where the rate constants $k_{11 f}$ and $k_{11 b}$ correspond to the reaction $\mathrm{HO}_{2}+\mathrm{OH} \stackrel{11}{\rightleftharpoons} \mathrm{H}_{2} \mathrm{O}+\mathrm{O}_{2}$.

\section{THE TWO-STEP REDUCED MECHANISM FOR $\mathrm{CH}_{4}$ OXIDATION}

\section{The Limit of Slow CO Oxidation}

CO oxidation is the slowest of the four chemical processes represented by $\mathrm{I}^{\prime}-\mathrm{IV}^{\prime}$ [5]. To illustrate this, one can use Eq. 1 to give the characteristic chemical-time ratios $t_{\mathrm{I}^{\prime}} / t_{\mathrm{IV}^{\prime}}=k_{17 f} /$ $\left(k_{34 f} K_{3}\right), t_{\mathrm{II}^{\prime}} / t_{\mathrm{IV}^{\prime}}=k_{17 f} /\left(k_{1 f} K_{3}\right)$, and $t_{\mathrm{III}^{\prime}} / t_{\mathrm{IV}}$ $=k_{17 f} /\left(k_{6 f}[\mathrm{M}] K_{3}\right)$. These simplified expressions, independent of the mixture composition, follow from assuming, as a first guess, that in the reaction zone the concentration of reactants is comparable to that of water vapor, and also that the concentration of carbon monoxide is comparable to that of molecular hydrogen. From these estimates, it can be seen that at the temperatures and pressures typical of gas-turbine combustion the scaling law $t_{\mathrm{I}^{\prime}} \sim t_{\mathrm{II}} \sim t_{\mathrm{III}}$ $\ll t_{\mathrm{IV}}$, holds. For instance, at $T=1700 \mathrm{~K}$ and $p=18 \mathrm{~atm}$, and with a third-body efficiency equal to 0.4 introduced in computing [M], the above expressions give $t_{\mathrm{I}^{\prime}} / t_{\mathrm{IV}^{\prime}}=0.01, t_{\mathrm{II}^{\prime}} / t_{\mathrm{IV}^{\prime}}=$ 0.016 and $t_{\mathrm{III}} / t_{\mathrm{IV}^{\prime}}=0.037$. As a direct consequence of these relative scalings we find the flame structure observed in Fig 1; fuel consumption followed by radical branching and radical recombination all occur in a thin layer that exhibits small concentrations of $\mathrm{H}_{2}$ and radicals, while $\mathrm{CO}$ oxidation is much slower, and consequently occurs in a distributed manner in a downstream region where in the first approximation $\left[\mathrm{CH}_{4}\right]=0$ and both $\mathrm{H}_{2}$ and $\mathrm{OH}$ maintain steady state [5]. Because of fast radical removal through reaction $\mathrm{I}^{\prime}$, all chemical activity is frozen in the preheat zone upstream from the fuel-consumption layer [1]. Note that the relatively fast rate of radical recombination (represented by the condition $t_{\mathrm{III}} / t_{\mathrm{IV}^{\prime}} \ll 1$ ), 
which leads to a steady-state approximation for $\mathrm{H}_{2}$ in the CO-oxidation region, is a consequence of the existing high-pressure conditions, which enhance $\mathrm{H}_{2}$ consumption through reaction III'. Therefore, while the $\mathrm{H}_{2}$ mol fraction is typically comparable in magnitude to the $\mathrm{CO}$ mol fraction in atmospheric flames, it exhibits in this high-pressure case a peak value an order of magnitude smaller than that of $\mathrm{CO}$.

The overall step occurring in the thin fuelconsumption layer can be obtained by eliminating $\mathrm{H}_{2}$ and $\mathrm{OH}$ by linear combinations of $\mathrm{I}^{\prime}-\mathrm{III}^{\prime}$ to give

$$
\mathrm{CH}_{4}+\frac{3}{2} \mathrm{O}_{2} \rightarrow \mathrm{CO}+2 \mathrm{H}_{2} \mathrm{O} \text {. }
$$

On the other hand, incorporating the steady states of $\mathrm{H}_{2}$ and $\mathrm{OH}$ into step $\mathrm{IV}^{\prime}$ by linear combinations with steps II' and III' provides the global CO-oxidation step

$\mathrm{CO}+\frac{1}{2} \mathrm{O}_{2} \rightleftharpoons \mathrm{CO}_{2}$.

Note that about one-third of the total heat is released by reaction $\mathrm{II}$, so that $\mathrm{CO}$ oxidation is fundamental for the self-sustained motion of the flame.

In the thin fuel-consumption layer where fuel attack by radicals takes place, giving as a result the overall reaction $\mathrm{I}$, neither the $\mathrm{H}_{2}-\mathrm{O}_{2}$ radicals nor $\mathbf{H}_{2}$ follow a steady-state approximation. Therefore, utilizing $\omega_{\mathrm{I}}=\omega_{\mathrm{I}^{\prime}}$ for the rate of reaction $I$, with the radical concentrations evaluated from appropriate steady-state expressions, leads to unacceptable inaccuracies in calculations of flame propagation velocities. As previously discussed, this characteristic precludes in principle the use of reduced mechanisms with less than four steps, and requires the detailed description of the very thin fuel-consumption layer if flame propagation velocities are to be reproduced. To circumvent this difficulty, we propose to represent $\omega_{\text {I }}$ by a heuristic Arrhenius law, given below in Eq. 15, that is seen to adequately reproduce the steady flame propagation velocity and the flame response to strain under a wide range of conditions. On the other hand, the rate of reaction II is given by

$$
\omega_{\mathrm{II}}=\omega_{\mathrm{IV}^{\prime}}=k_{17 f}[\mathrm{CO}][\mathrm{OH}]-k_{17 b}\left[\mathrm{CO}_{2}\right][\mathrm{H}] \text {. }
$$

As shown below, the $\mathrm{CO}$-oxidation rate given in Eq. 5 describes accurately the nonequilibrium evolution of the $\mathrm{CO}$ concentration, as well as its associated radical pool (through appropriate steady-state expressions), downstream from the fuel-consumption layer, with the failure of the steady-state approximations for $\mathrm{OH}$ and $\mathrm{H}_{2}$ within the thin fuel-consumption layer having only a very limited effect.

\section{Steady-State Expressions for $\mathrm{H}_{2}$ and $\mathrm{OH}$}

To completely define the rate given in Eq. 5, the concentrations of $\mathrm{OH}$ and $\mathrm{H}$ must be calculated in terms of the temperature and of the concentrations of $\mathrm{O}_{2}, \mathrm{CO}, \mathrm{CO}_{2}$, and $\mathrm{H}_{2} \mathrm{O}$. In the $\mathrm{CO}$-oxidation region, the corresponding steadystate equations for $\mathrm{H}_{2}$ and $\mathrm{OH}$ with $\left[\mathrm{CH}_{4}\right]=0$, $-\omega_{\mathrm{II}}-\omega_{\mathrm{III}}+\omega_{\mathrm{IV}^{\prime}}=0$ and $2 \omega_{\mathrm{II}^{\prime}}-2 \omega_{\mathrm{III}^{\prime}}=0$, can be solved to give the expression

$$
\begin{aligned}
{\left[\mathrm{H}_{2}\right]=} & K_{3}^{-1}\left[\mathrm{O}_{2}\right]^{-1} \alpha_{1}\left\{\left(K_{4} / K_{1}\right)[\mathrm{OH}]^{2}\right. \\
& \left.+\frac{1}{2}\left(k_{17 f} / k_{1 f}\right)[\mathrm{CO}]\left[\mathrm{H}_{2} \mathrm{O}\right]\right\},
\end{aligned}
$$

together with the fourth-order polynomial

$$
\begin{aligned}
a_{4}[\mathrm{OH}]^{4} & +a_{3}[\mathrm{OH}]^{3}+a_{2}[\mathrm{OH}]^{2}+a_{1}[\mathrm{OH}]^{1} \\
& +a_{0}=0,
\end{aligned}
$$

where we have introduced the coefficients

$$
\begin{aligned}
& a_{4}=-\left(K_{4} k_{11 f} / K_{1}\right)\left[1-\alpha_{1}(1-\gamma)\right], \\
& a_{3}=-\left(K_{4} k_{6 b} / K_{1}\right)\left[1-\alpha_{1}\right][\mathrm{M}], \\
& a_{2}=\frac{1}{2} \alpha_{1}\left(k_{17 f} k_{11 f} / k_{1 f}\right)(1-\gamma)[\mathrm{CO}]\left[\mathrm{H}_{2} \mathrm{O}\right], \\
& a_{1}=\frac{1}{2} \alpha_{1}\left(k_{17 f} k_{6 b} / k_{1 f}\right)[\mathrm{M}][\mathrm{CO}]\left[\mathrm{H}_{2} \mathrm{O}\right], \\
& a_{0}=\left(k_{6 b} k_{11 b} / k_{1 f}\right)[\mathrm{M}]\left[\mathrm{H}_{2} \mathrm{O}\right]^{2}\left[\mathrm{O}_{2}\right]
\end{aligned}
$$

and the functions

$\alpha_{1}=\left(1+\frac{1}{2} \frac{k_{17 b}}{k_{1 f}} \frac{\left[\mathrm{CO}_{2}\right]}{\left[\mathrm{O}_{2}\right]}\right)^{-1}$

and

$\gamma=k_{6 f}[\mathrm{M}] / k_{1 f}$

Once Eq. 7 is solved for [OH], use can be made of Eq. 6 to compute $\left[\mathrm{H}_{2}\right]$ and of Eqs. 2 and 3 to calculate $[\mathrm{H}]$ and $[\mathrm{O}]$. 
Expressing $[\mathrm{OH}]$ through the polynomial given in Eq. 7 is a necessary complication if one wants to accurately describe the chemical equilibrium state, as it is especially desirable in configurations with nonnegligible NO production in the postflame region. The simpler explicit steady-state expressions

$$
\left[\mathrm{H}_{2}\right]=\frac{1}{2} \frac{k_{17 f} \alpha_{2}}{k_{6 f}[\mathrm{M}] K_{3}} \frac{\left[\mathrm{H}_{2} \mathrm{O}\right][\mathrm{CO}]}{\left[\mathrm{O}_{2}\right]}
$$

and

$$
\begin{aligned}
{[\mathrm{OH}]=} & \left(\frac{1}{2} \frac{k_{17 f} K_{1}(1-\gamma) \alpha_{2}}{k_{6 f}[\mathrm{M}] K_{4}}\right)^{1 / 2} \\
& \cdot\left[\mathrm{H}_{2} \mathrm{O}\right]^{1 / 2}[\mathrm{CO}]^{1 / 2}
\end{aligned}
$$

where

$\alpha_{2}=\left(1+\frac{1}{2} \frac{k_{17 b}}{k_{6 f}[\mathrm{M}]} \frac{\left[\mathrm{CO}_{2}\right]}{\left[\mathrm{O}_{2}\right]}\right)^{-1}$,

which are obtained by neglecting the reverse of reaction III', are however, a very good approximation in the initial part of the CO-oxidation region. Equations 11 and 12 can be utilized to express Eq. 5 in the compact form

$$
\omega_{\mathrm{II}}=\left(\frac{k_{17 f}^{3} K_{1}(1-\gamma) \alpha_{2}^{3}}{2 k_{6 f}[\mathrm{M}] K_{4}}\right)^{1 / 2}\left[\mathrm{H}_{2} \mathrm{O}\right]^{1 / 2}[\mathrm{CO}]^{3 / 2},
$$

a simplified expression for the CO-oxidation rate corresponding to the limit of irreversible radical recombination. It will be shown below that this alternative description is able to reproduce well peak values of $\mathrm{CO}$ and radicals, but becomes increasingly inaccurate as the $\mathrm{CO}$ concentration decreases, giving in particular $[\mathrm{CO}]$ $=\left[\mathrm{H}_{2}\right]=[\mathrm{OH}]=0($ and also $[\mathrm{H}]=[\mathrm{O}]=0$ by virtue of Eqs. 2 and 3) as the equilibrium state obtained as solution of $\omega_{\text {II }}=0$. This is the limitation that precludes the use of Eq. 14 in systems with nonnegligible postflame NO production. It is worth remarking that the $\mathrm{CO}$ oxidation rate employed in the analysis of $\mathrm{Li}$ et al. [6] differs from that given in Eq. 14 in that the backward rate of reaction 17 is neglected, and the rate of the branching reaction $1 f$ is assumed to be much faster than that of the recombination reaction $6 f$, thereby yielding an even simpler rate expression with $\alpha_{2}=1$ and $\gamma=0$.

\section{The Rate of Fuel Consumption}

As previously discussed, reaction I takes place in a very thin layer where neither radicals nor $\mathrm{H}_{2}$ follows a steady-state approximation, and where the partial equilibrium assumptions leading to Eqs. 2 and 3 also fail. Clearly, the overall rate at which fuel is converted into CO not only

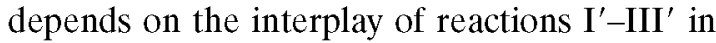
the thin fuel-consumption layer, but also on the solution in the preheat and CO-oxidation regions. These dependences complicate the derivation of a rate expression for reaction I. As a remedy that provides satisfactory results, we propose the heuristic law

$\omega_{\mathrm{I}}=B Y_{\mathrm{CH}_{4}} Y_{\mathrm{O}_{2}}^{2.5}\left(p / p_{o}\right)^{0.5} \exp \left(-T_{a} / T\right)$

for the fuel-consumption rate. As shown below, use of this functional form, which incorporates explicit dependences on fuel and oxygen mass fractions, $Y_{\mathrm{CH}_{4}}$ and $Y_{\mathrm{O}_{2}}$, temperature, and pressure, produces excellent agreement in values of flame propagation velocities and of critical strain rates at extinction. Discussion on the selection procedure for the different reactionrate parameters is given below.

The rate $\omega_{I^{\prime}}$ in Eq. 1 suggests a unity reaction order with respect to fuel, which motivates the selection used in Eq. 15. As for the scaling pressure $p_{o}$, its value is in principle arbitrary, i.e., changes in $p_{o}$ can be readily absorbed in the preexponential factor $B$. The value of $B$ given below corresponds in particular to $p_{o}=18$ bar. The selection of $B$ and of the remaining reaction-rate parameters was largely based on comparisons of flame propagation velocities, $u_{l}$, obtained with the two-step mechanism with results of detailed-chemistry computations. Agreement in computations of laminar propagation velocities seems to be a minimum requirement for the two-step mechanism. It is expected that, if the mechanism is able to describe $u_{l}$, then it will also be able to describe with reasonable accuracy the location of the fuel-consumption layer in the combustion chamber.

Following this rationale, the 2.5 reaction order with respect to the oxidizer was adjusted to reproduce flame propagation velocities near stoichiometric conditions. Similarly, the $p^{0.5} \mathrm{de}-$ 
pendence of the fuel-consumption rate was determined by comparing the variation of $u_{l}$ with $p$ for given conditions of temperature and composition of the reactant mixture. It is worth mentioning that this last dependence can also be rationally derived in cases where the elementary reaction $\mathrm{CH}_{4}+\mathrm{H} \underset{34}{\rightarrow} f \mathrm{CH}_{3}+\mathrm{H}_{2}$ is the main fuel-consumption rate-limiting step. Assuming that the steady-state expressions given in Eqs. 11 and 12 hold in the fuel-consumption layer, it then follows from Eq. 2 that the concentration of $\mathrm{H}$ atoms is proportional to the reciprocal of the square root of the pressure. Introducing this result into the rate of $34 f$, with the fuel concentration being linearly proportional to the pressure, finally yields the $p^{0.5}$ dependence shown in Eq. 15.

With the other parameters fixed, only the activation temperature, $T_{a}$, and the preexponential factor, $B$, remain to be selected. The value of $T_{a}$ must be sufficiently large to produce a relatively thin fuel-consumption layer, in agreement with the results shown in Fig. 1, although an exceedingly large value introduces unnecessary numerical stiffness in the resulting flowfield calculations. For a given $T_{a}$, the accompanying value of $B$ was determined by matching exactly the value of $u_{l}$ obtained with detailed chemistry for a specific set of flowfield conditions, namely, $p=18$ bar, $T_{u}=$ $800 \mathrm{~K}$ and $\phi=0.6\left(u_{l}=45.24 \mathrm{~m} / \mathrm{s}\right)$. Values of the activation temperature ranging from six times the adiabatic flame temperature up to roughly 20 times this value were investigated. It was observed that, for all pairs $\left(T_{a}, B\right)$ selected according to the above procedure, the computations of other flames gave values of $u_{l}$ with errors smaller than $20 \%$ over a wide range of conditions of pressure, temperature, and composition. The final values selected for the computations shown below, $T_{a}=22,850 \mathrm{~K}$ and $B=5.46 \times 10^{9} \mathrm{~mol} \mathrm{~cm}^{-3} \mathrm{~s}^{-1}$, were seen to give the best agreement in $u_{l}$, while showing reasonably rapid numerical convergence in the calculations. As discussed below in relation to nonadiabatic stretched flames, the value of $T_{a}$ selected proved to be large enough for the accurate description of extinction phenomena.

\section{Radical Consumption by Fuel Attack}

As previously explained, radical removal through fuel attack ensures a chemically frozen preheat region where $\mathrm{CO}$ oxidation does not occur. To incorporate this important effect, which is not reproduced by the present model due to the choice for the fuel-consumption rate given in Eq. 15, an appropriate cutoff must be incorporated in Eq. 5. To guide the selection of this cutoff, it is instructive to momentarily assume that $\mathrm{OH}$ maintains steady state in the fuel-consumption layer. Solving for $-2 \omega_{\mathrm{I}^{\prime}}+$ $2 \omega_{\mathrm{II}}-2 \omega_{\mathrm{III}}=0$ with the reverse of reaction III' neglected and with reaction $34 f$ assumed to be faster than $36 f$ yields

$$
\begin{aligned}
{[\mathrm{OH}]=} & \left\{\frac{K_{1} K_{3}}{K_{4}}(1-\gamma)\left[\mathrm{O}_{2}\right]\left[\mathrm{H}_{2}\right]\right\}^{1 / 2} \\
& \cdot\left(1-\frac{k_{34 f}\left[\mathrm{CH}_{4}\right]}{(1-\gamma) k_{1 f}\left[\mathrm{O}_{2}\right]}\right)^{1 / 2} .
\end{aligned}
$$

Observation of the last term in brackets in this equation reveals that radical depletion occurs when the fuel concentration increases to a cutoff value given by

$\left[\mathrm{CH}_{4}\right]_{c}=(1-\gamma) k_{1 f}\left[\mathrm{O}_{2}\right] / k_{34 f}$.

Because the concentration of $\mathbf{H}$ atoms is linearly proportional to $[\mathrm{OH}]$, this consideration suggests that the effect of radical consumption by fuel attack can be incorporated in the model in a straightforward manner by multiplying the CO-oxidation rate given in Eq. 5 (or that given in $\mathrm{Eq} .14$ if irreversible radical recombination is assumed $)$ by the expression $\left(1-\left[\mathrm{CH}_{4}\right] /\right.$ $\left.\left[\mathrm{CH}_{4}\right]_{c}\right)^{1 / 2}$ appearing in Eq. 16. As discussed in Ref. 8, this first option introduces complications in the numerical treatment of the problem; the resulting radical profiles abruptly decrease to zero, exhibiting a nonzero gradient at the depletion point. In selecting an alternative multiplicative factor, different smooth functional forms, and also different cutoff fuel concentrations with the effect of reaction $36 f$ included, were investigated. The computations of laminar flames showed that the results were quite insensitive to the cutoff selection. Among the different options that provide radical profiles smoothly decaying to zero across the fuel con- 
sumption layer, the simple multiplicative factor $\left(1+\frac{1}{2}\left[\mathrm{CH}_{4}\right] /\left[\mathrm{CH}_{4}\right]_{c}\right)^{-1}$, with $\left[\mathrm{CH}_{4}\right]_{c}$ given in Eq. 17, is used for the computations shown in the paper.

\section{THE REDUCED MECHANISM FOR NO PRODUCTION}

Computations of laminar flames with detailed nitrogen chemistry indicated that reactions N27-N29 are extremely slow under the conditions investigated, and give negligibly small concentrations of $\mathrm{NO}_{2}$ (typically two orders of magnitude smaller than that of NO). Consequently, reactions $\mathrm{N} 27-\mathrm{N} 29$ were neglected, along with the contribution of $\mathrm{NO}_{2}$ to the total $\mathrm{NO}_{x}$ production. On the other hand, it was seen that the consumption of $\mathrm{NH}_{2}, \mathrm{HNO}, \mathrm{NH}, \mathrm{N}_{2} \mathrm{H}$, and $\mathrm{N}$ is fast enough that all these intermediates maintain steady state everywhere, so that the nitrogen chemistry reduces to the two overall steps

$\mathrm{N}_{2}+\mathrm{O}_{2} \rightarrow 2 \mathrm{NO}$

and

$\mathrm{N}_{2}+\frac{1}{2} \mathrm{O}_{2} \rightarrow \mathrm{N}_{2} \mathrm{O}$

The rates of these two global reactions are given by

$$
\begin{aligned}
\omega_{\mathrm{NI}}= & k_{\mathrm{N} 11 b}[\mathrm{H}]\left[\mathrm{N}_{2} \mathrm{O}\right]+k_{\mathrm{N} 12 b}[\mathrm{OH}]\left[\mathrm{N}_{2}\right] \\
& +k_{\mathrm{N} 18 b}[\mathrm{O}]\left[\mathrm{N}_{2}\right]+k_{\mathrm{N} 25}[\mathrm{O}]\left[\mathrm{N}_{2} \mathrm{O}\right]
\end{aligned}
$$

and

$$
\begin{aligned}
\omega_{\mathrm{NII}}= & -k_{\mathrm{N} 11 b}[\mathrm{H}]\left[\mathrm{N}_{2} \mathrm{O}\right]-k_{\mathrm{N} 21 b}[\mathrm{H}]\left[\mathrm{N}_{2} \mathrm{O}\right] \\
& -k_{\mathrm{N} 23 f}\left[\mathrm{~N}_{2} \mathrm{O}\right][\mathrm{M}]+k_{\mathrm{N} 23 b}\left[\mathrm{~N}_{2}\right][\mathrm{O}][\mathrm{M}] \\
& -k_{\mathrm{N} 24 f}\left[\mathrm{~N}_{2} \mathrm{O}\right][\mathrm{H}]-k_{\mathrm{N} 25}[\mathrm{O}]\left[\mathrm{N}_{2} \mathrm{O}\right] .
\end{aligned}
$$

In these rate expressions, only those elementary reactions that give a nonnegligible contribution have been retained. More specifically, we have neglected reactions $\mathrm{N} 3, \mathrm{~N} 11 f, \mathrm{~N} 12 f$, and $\mathrm{N} 18 f$ in $\omega_{\mathrm{NI}}$ and reactions $\mathrm{N} 11 f$, N21f, $\mathrm{N} 24 b$, and N26 in $\omega_{\mathrm{NII}}$, because their collective contribution amounts to less than $2 \%$ of the corresponding global rates. As previously mentioned, the nitrogen chemistry is very slow, so that the amount of radicals and $\mathrm{N}_{2}$ consumed through NO production is insignificant. To evaluate Eqs. 18 and 19 , one can consequently use the concentrations of $\mathrm{H}, \mathrm{O}$, and $\mathrm{OH}$ determined from Eqs. 2, 3, and 7, and neglect $\mathrm{N}_{2}$ consumption altogether.

In previous analyses of $\mathrm{NO}_{x}$ emissions [13], the intermediate $\mathrm{N}_{2} \mathrm{O}$ was also assumed to maintain steady state, an approximation that is valid sufficiently far downstream from the flame front. The mechanism then simplifies to the single overall step NI, with the concentration of $\mathrm{N}_{2} \mathrm{O}$ appearing in Eq. 18 evaluated from its steady-state expression, which can be computed in this case by equating to zero Eq. 19 to yield

$$
\begin{aligned}
{\left[\mathrm{N}_{2} \mathrm{O}\right]=} & k_{\mathrm{N} 23 b}\left[\mathrm{~N}_{2}\right][\mathrm{O}][\mathrm{M}] /\left\{\left(k_{\mathrm{N} 11 b}+k_{\mathrm{N} 21 b}\right.\right. \\
& \left.\left.+k_{\mathrm{N} 24 f}\right)[\mathrm{H}]+k_{\mathrm{N} 23 f}[\mathrm{M}]+k_{\mathrm{N} 25}[\mathrm{O}]\right\} .
\end{aligned}
$$

An approximation of this type was seen to be adequate for diffusion flames [13], and will be shown to also provide reasonably accurate results for NO production in lean premixed flames under most conditions, with overpredictions being always relatively small.

\section{DESCRIPTION OF FREELY PROPAGATING PLANAR FLAMES}

The reduced kinetics proposed here is now used to compute 1D laminar flames under different conditions. Results corresponding to freely propagating flames are presented in this section, while calculations of stretched flames are left for the following section. As previously mentioned, the simplicity of the flowfield configurations selected enable also calculations with the detailed chemistry exhibited in Appendixes $A$ and $B$, and the results of the two approaches can then be mutually compared. In comparing both sets of results, one should bear in mind that a detailed transport description [12] was utilized in the detailed chemistry calculations, while unity Lewis numbers for all chemical species not following a steady-state approximation was assumed in the reducedchemistry computations. Although these preliminary tests show excellent agreement be- 

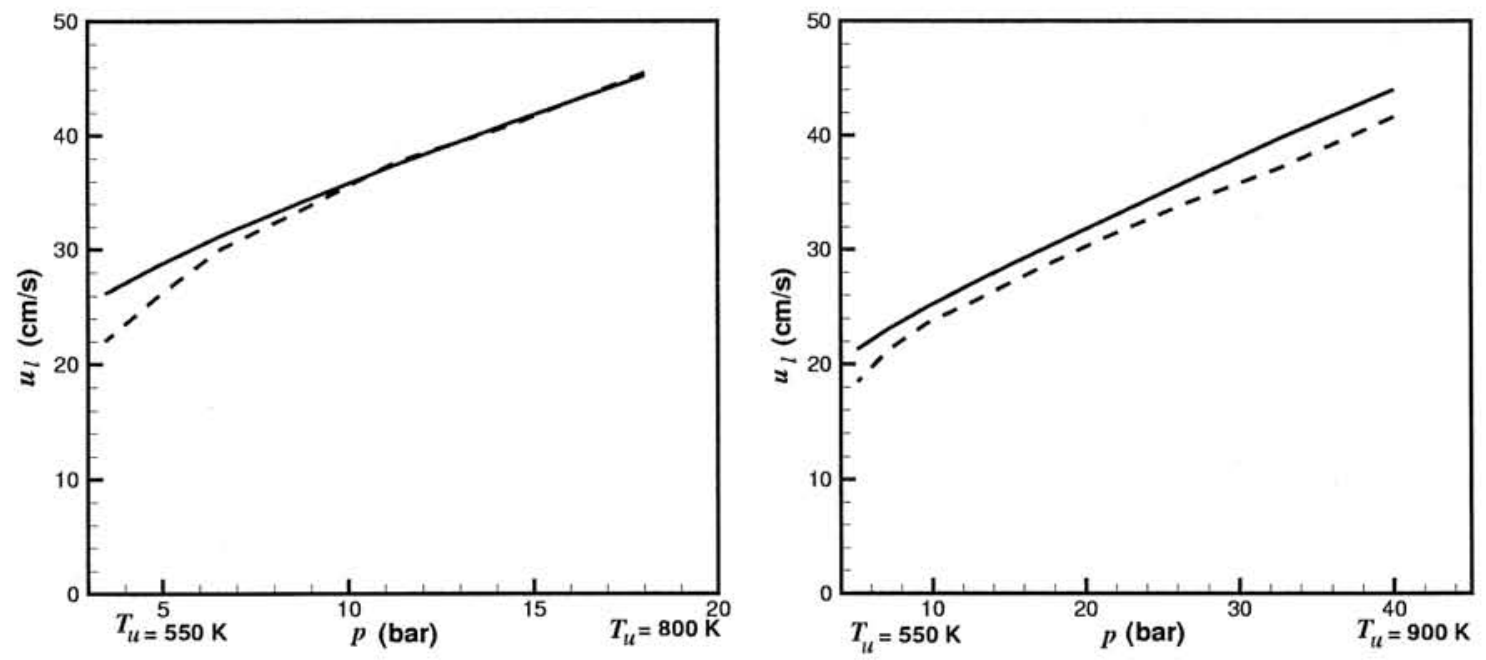

Fig. 2. The flame propagation velocity for $\phi=0.6$ as obtained with detailed chemistry description (solid lines) and with reduced kinetics (dashed lines).

tween the results of the reduced mechanism and those of the detailed chemistry, further comparisons, including both unsteady and curvature effects, would be necessary to guarantee the validity of the reduced kinetic description.

\section{Flame Propagation Velocity}

An important characteristic of laminar premixed flames, often used as a global performance test for reduced mechanisms, is the flame propagation velocity, $u_{l}$. With the reaction-rate parameters selected above for the fuel-consumption rate, the calculation of planar flames with the reduced kinetics results in errors in $u_{l}$ typically smaller than $10 \%$ for varying conditions of mixture composition, temperature, and pressure. This is illustrated in Figs. 2 and 3 , where the value of $u_{l}$ obtained with the reduced mechanism is compared with that obtained with detailed chemistry.

Figure 2 considers the effect of pressure and temperature for a mixture with $\phi=0.6$, with the values of $p$ and $T_{u}$ corresponding to an isentropic compression from sea-level conditions (right-hand side plot) and from conditions at an altitude of 11,000 m (left-hand side plot). The maximum compression ratios considered in these two plots are those typical of takeoff ( $p=$ 40 bar and $\left.T_{u}=900 \mathrm{~K}\right)$ and cruise $(p=18$ bar and $\left.T_{u}=800 \mathrm{~K}\right)$ operations, respectively.
Observation of this figure indicates that the reduced kinetics captures the increase in flame velocity for increasing compression ratios, with differences between the two calculated values being only a few centimeters per second over the whole range of pressures investigated.

A similar agreement is found for the dependence of the flame propagation velocity on the mixture composition. This is investigated in Fig. 3 , where we plot the variation of $u_{t}$ with equiv-

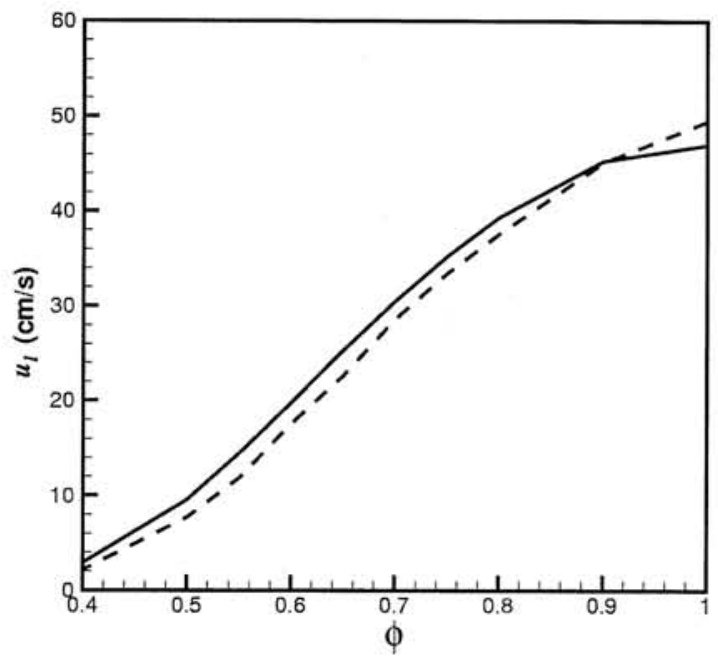

Fig. 3. The flame propagation velocity as a function of the equivalence ration for $p=7$ bar and $T_{u}=520 \mathrm{~K}$ as obtained with detailed chemistry (solid lines) and with the reduced kinetics (dashed lines). 

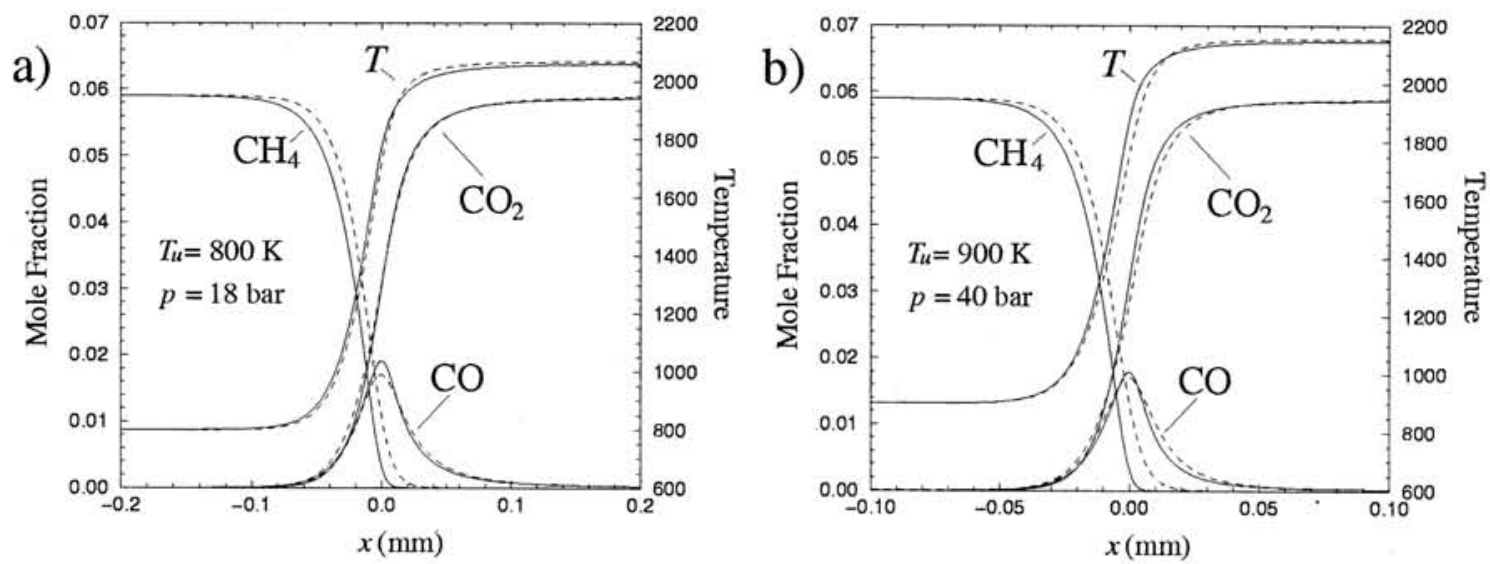

Fig. 4. Main species and temperature profiles for $\phi=0.6$ as obtained with the detailed chemistry description (solid lines) and with the reduced kinetics (dashed lines).

alence ratio for a lean mixture initially at $T_{u}=$ $520 \mathrm{~K}$ burning at $p=7$ bar. Although the reduced kinetics was specifically developed to reproduce combustion in lean environments, with the selection for the explicit oxidizer dependence $Y_{\mathrm{O}_{2}}^{2.5}$ of the fuel-consumption rate, agreement in $u_{l}$ is observed for conditions including those of stoichiometric mixtures. Given the relative simplicity of Eq. 15, and the fact that the selection of $T_{a}$ and $B$ was based on fitting a single value of $u_{l}$, the degree of agreement found over the wide range of conditions investigated in Figs. 2 and 3 is certainly satisfying.

\section{Flame Structure}

The characteristic flame structure corresponding to the reduced two-step model is shown in Fig. 4, along with the results of the detailedchemistry calculations. For the mutual comparisons of the results of the two approaches, the distance across the flame $x$ is measured from the location where the $\mathrm{CO}$ profile reaches its peak value. This criterion, adopted hereafter for all profile comparisons of freely propagating flames shown in this paper, removes the arbitrariness associated with the translational invariance of the planar flame. Adoption of a different origin for $x$, for example, the location where the value of the fuel concentration decreases to half of its initial value, would result in a small relative translation of the different profiles by an amount of the order of the fuel-consumption layer thickness.

As can be observed in Fig. 4, there exists good agreement in profiles of main species and temperature. In particular, the two-step model adequately reproduces the shape of the $\mathrm{CO}$ profile, with peak values differing only by a small amount in the two cases considered. This agreement is further illustrated in Figs. 5a-b, where a logarithmic scale is utilized to show how the proposed formulation remains accurate as equilibrium is approached downstream from the flame. As can be seen in Figs. $5 \mathrm{c}-\mathrm{h}$, the agreement extends to profiles of $\mathrm{OH}, \mathrm{O}$, and $\mathrm{H}$, with the two-step model describing well the profile evolution towards equilibrium. Failure of the steady-state assumptions for radicals and $\mathrm{H}_{2}$ within the fuel-consumption layer introduces small inaccuracies in peak radical concentrations, with departures being somewhat larger for $\mathrm{H}$ atoms. As can be observed, radical profiles peak slightly downstream from the location of maximum $\mathrm{CO}$ concentration. This characteristic, that follows from the inner structure of the fuel-consumption layer [1], is accurately reproduced by the two-step model through the introduction of radical consumption by fuel attack (the cutoff criterion previously discussed).

Another point of interest concerns the results corresponding to $p=40 \mathrm{bar}$ and $T_{u}=900 \mathrm{~K}$, a case for which the flame velocity calculated with reduced kinetics $\left(u_{l}=41.63 \mathrm{~cm} / \mathrm{s}\right)$ is smaller than that calculated with detailed chem- 

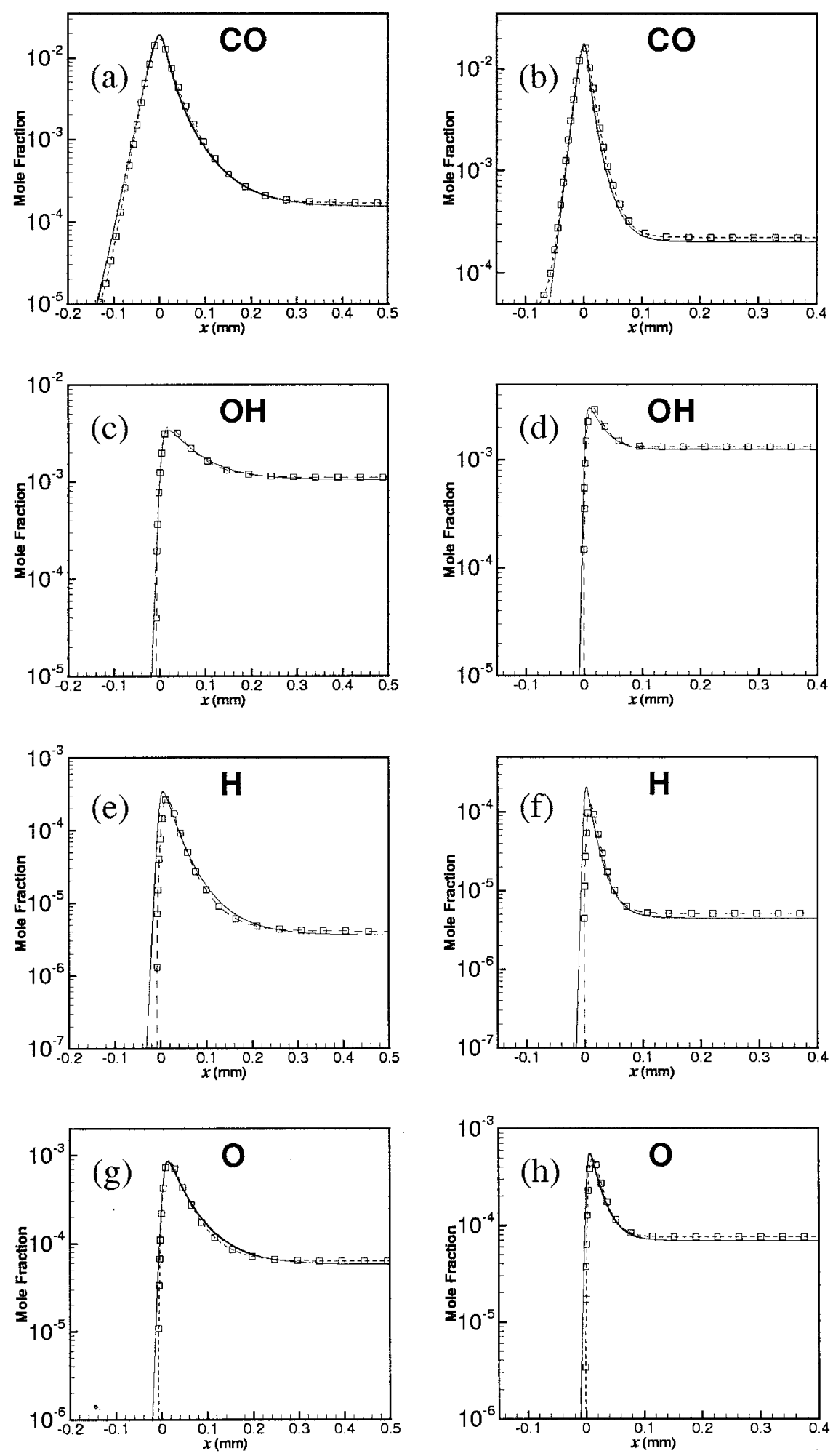

Fig. 5. Mol fractions of relevant intermediates as obtained with detailed chemistry (solid lines) and with the reduced kinetics (symbols) for $p=18 \mathrm{bar}, T_{u}=800 \mathrm{~K}$, and $\phi=0.6$ (left-hand side plots) and for $p=40 \mathrm{bar}, T_{u}=900 \mathrm{~K}$, and $\phi=0.6$ (right-hand side plots). 
istry $\left(u_{l}=44.02 \mathrm{~cm} / \mathrm{s}\right)$. As can be seen, this discrepancy does not translate into a very large error when calculating the flame structure, suggesting that the inaccuracies in $u_{l}$ displayed in Figs. 2 and 3 are within an acceptable margin.

\section{Oxides of Nitrogen}

Profiles of $\mathrm{NO}$ and $\mathrm{N}_{2} \mathrm{O}$ mol fractions across the flame obtained with the reduced kinetics are compared in Fig. 6 with detailed-chemistry results. The plot reveals the existence of an initial region of rapid NO growth associated with superequilibrium radical concentrations, followed by a long tail with constant NO-production rate. As can be seen, with the accurate profiles of temperature and radicals determined with the reduced chemistry of fuel oxidation, both regions are accurately computed with the reduced nitrogen chemistry NI-NII.

The accuracy of the steady-state assumption for $\mathrm{N}_{2} \mathrm{O}$ is also analyzed in Fig. 6. As can be observed, although the $\mathrm{N}_{2} \mathrm{O}$ steady-state profile falls below that of the detailed calculations across the initial and final sections of the flame, it shows an intermediate peak value that is overpredicted by as much as $25 \%$. These inaccuracies partially cancel when calculating the NO production rate, so that discrepancies in NO profiles are somewhat smaller. In view of these results, we can then conclude that the one-step global reaction NI (with a rate determined by Eqs. 18 and 20) provides a reasonably good prediction for NO concentrations, although the two-step description NI-NII should be preferred in applications if increased accuracy is desired.

\section{The Limit of Irreversible Radical Recombination}

Neglecting the reverse of the radical-recombi-

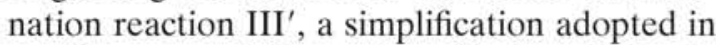
previous asymptotic analyses $[1,5]$ and also in the recent work of $\mathrm{Li}$ et al. [6], leads to the reduced $\mathrm{CO}$-oxidation rate previously given in Eq. 14. Because use of this more compact expression would somewhat reduce the effort required in computations, it is of interest to test the accuracy of the resulting approach. Thus, profiles of $\mathrm{CO}$ obtained by using Eq. 14 for the
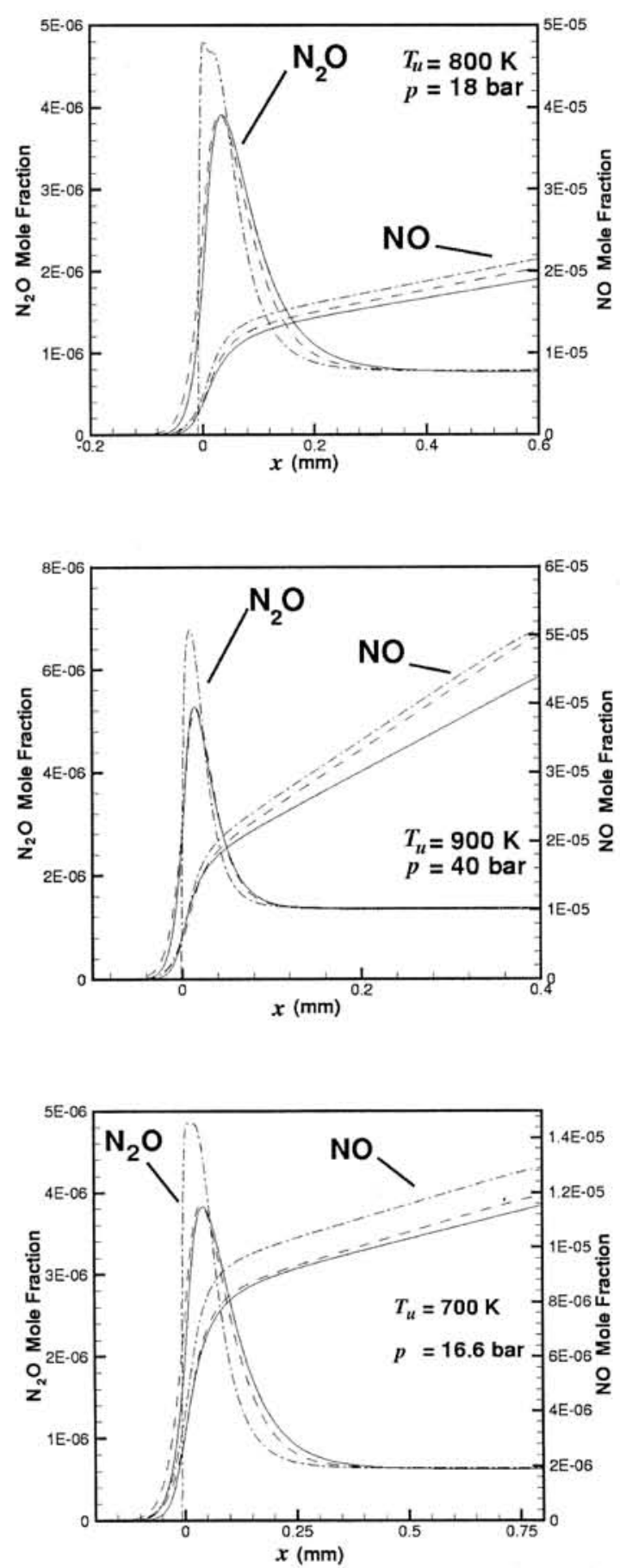

Fig. 6. The profiles $\mathrm{NO}$ and $\mathrm{N}_{2} \mathrm{O}$ mol fractions for $\phi=0.6$ as obtained with detailed chemistry (solid lines), with the complete reduced kinetics (dashed lines) and with the reduced kinetics with $\mathrm{N}_{2} \mathrm{O}$ in steady state (dot-dashed lines). 

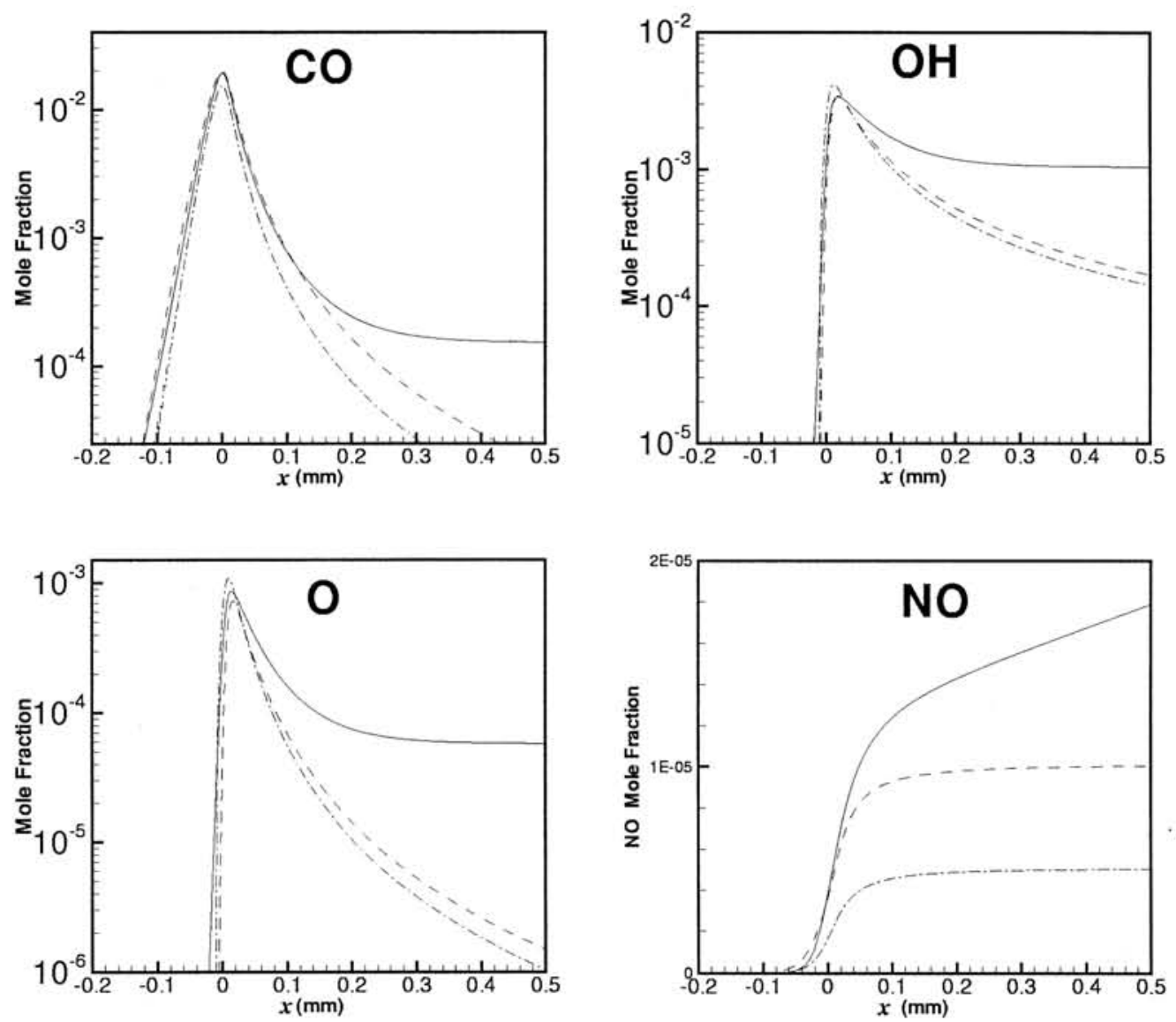

Fig. 7. Mol fractions of radicals and pollutants across a premixed flame with $p=18$ bar, $T_{u}=800 \mathrm{~K}$, and $\phi=0.6$, as obtained with detailed chemistry (solid lines), with the reduced chemistry in the limit or irreversible radical recombination (dashed lines), and with the additional approximations $\alpha_{2}=1, \gamma=0, \omega_{\mathrm{NI}}=k_{\mathrm{N} 18 b}[\mathrm{O}]\left[\mathrm{N}_{2}\right]$ (dot-dashed lines).

CO-oxidation rate are plotted in Fig. 7, along with profiles of radicals obtained from Eq. 12. The comparison with the results obtained with detailed chemistry indicates that the simplified rate adequately describes the peak value and the initial decrease of the $\mathrm{CO}$ profiles, with the agreement being satisfactory over about two orders of magnitude in $\mathrm{CO}$ mol fraction. However, with irreversible radical recombination, the resulting description fails to reproduce the final equilibrium value, approaching instead a zero $\mathrm{CO}$ concentration far downstream from the flame. A similar behavior is found for the radical profiles, with significant departures appearing at somewhat smaller distances.

The inaccuracies in the radical-pool description readily affect the nitrogen chemistry through the rate dependences on radical concentrations, an effect that is also exhibited in
Fig. 7. As can be observed, the NO profile calculated in the limit of irreversible radical recombination exhibits large errors that are especially noticeable in the quasi-equilibrium region that extends downstream.

From the laminar results presented here it can be concluded that, although the assumption of irreversible radical recombination greatly simplifies the reduced kinetics, it introduces inaccuracies in predictions of $\mathrm{CO}$ and $\mathrm{NO}$ emissions that are in general too large. As can be expected, even larger errors arise when further chemistry simplifications are made. For instance, the additional approximations of negligible $\mathrm{CO}_{2}$ consumption through $17 b\left(\alpha_{2}=1\right)$, slow radical recombination $(\gamma=0)$ and NO production exclusively controlled by the thermal path through the elementary reaction $18 b$ $\left(\omega_{\mathrm{NI}}=k_{\mathrm{N} 18 b}[\mathrm{O}]\left[\mathrm{N}_{2}\right]\right)$ are also tested in Fig. 7. 
Although the errors introduced through the simplifications of $\gamma$ and $\alpha_{2}$ in Eq. 14 partially compensate, a further decrease is seen in the resultant $\mathrm{CO}$ and radical mol fractions. The larger errors seen in the NO profile are only partially due to the reduced $\mathrm{O}$ concentration, with discrepancies being instead mainly attributable to the elementary reactions omitted in $\omega_{\mathrm{NI}}$.

\section{CALCULATIONS OF STRETCHED FLAMES}

The flow field that exists in gas-turbine combustion chambers is characterized by the existence of large recirculating regions of hot products. Combustion typically takes place in strained mixing layers that form between these recirculating hot products and the incoming fresh mixture, generating a very complex turbulent reactive flow field where local flame stretch plays a determinant role. To characterize the effects of flame stretch on lean premixed flames, and elucidate whether the reduced kinetics describes all of these effects, we consider here the planar flow field that emerges when a stream of methane and air is counterflowing against a stream of its combustion products. This fresh-to-burnt stagnation point flow configuration has been widely used in previous studies $[15,16]$. The steady solution to this problem, which depends only on the distance $x$ to the stagnation plane, can be studied in the boundary-layer approximation [3], resulting in a problem that was integrated numerically with both detailed and reduced chemistry. As for the case of unstrained flames, a detailed transport description [12] was employed in the detailed-chemistry calculations presented below, while results of the reduced kinetics incorporate a unity-Lewis-number approximation for the transport of all chemical species. Nonadiabatic flames with temperatures of the products stream below the adiabatic flame temperature were considered along with adiabatic flames.

\section{Effect of Strain}

The results depend on the strain rate that is imposed by the outer streams. For definiteness in comparisons, we choose to characterize the strain field by its corresponding value on the reactant side of the mixing layer, $a$. The effect of increasing $a$ is illustrated in Fig. 8, where profiles of main species and temperature across the mixing layer are plotted for three different values of $a$, with solid and dashed lines representing, respectively, results obtained with detailed chemistry and with the reduced kinetics. As can be seen, the reactant stream approaches from $x=-\infty$, thereby facilitating comparisons with the profiles of freely propagating flames previously shown. The cases exhibited in Fig. 8 correspond to an adiabatic flame with $p=18$ bar. The temperature and equivalence ratio of the reactant stream are $T_{u}=800 \mathrm{~K}$ and $\phi=0.6$, respectively.

The dependence of the solution on $a$ can be adequately represented in dimensionless form through a Damköhler number $u_{l}^{2} /\left(a D_{T}\right)$, where $u_{l}$ and $D_{T}$ represent, respectively, the flame propagation velocity of the reactant mixture and the thermal diffusivity at the adiabatic flame temperature, with both quantities evaluated at the given pressure. Equivalently, one can characterize the effect of strain through the Karlowitz number $\kappa=a D_{T} / u_{l}^{2}$, the inverse of the previously defined Damköhler number. The values of $\kappa$ corresponding to the three cases $a=$ $(4000,40,000,200,000) \mathrm{s}^{-1}$ shown in Fig. 8 are, respectively, $\kappa \simeq(0.66,6.6,33)$. It must be noticed that, due to thermal expansion, the local strain rate experienced in the reaction zone is somewhat smaller than that of the reactant stream, which is the value employed in the definition of $\kappa$. Consequently, the Karlowitz number calculated here overestimates the effect of strain, so that, for instance, a moderately small value of $\kappa=0.66$ corresponds actually to a flame that is very weakly strained, as seen below.

The Karlowitz number can be interpreted as the ratio of the chemical time $D_{T} / u_{l}^{2}$ to the strain time $a^{-1}$. Alternatively, it may also be interpreted as the square of the ratio of the characteristic flame thickness $D_{T} / u_{l}$ to the characteristic mixing-layer thickness $\left(D_{T} / a\right)^{1 / 2}$ or as the square of the ratio of the characteristic mixing-layer velocity $\left(D_{T} a\right)^{1 / 2}$ to $u_{\eta}$. Use of all of these interpretations helps to understand how sufficiently small values of $\kappa$ correspond to flames that are only weakly affected by strain, i.e., the associated flames are thin compared with the mixing-layer thickness and lie away from the stagnation plane, at a location where the local flow velocity equals $u_{l}$. A weakly 


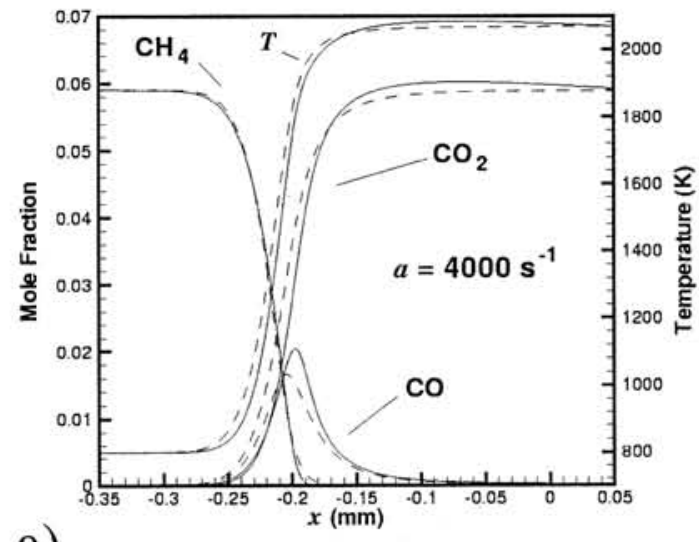

a)

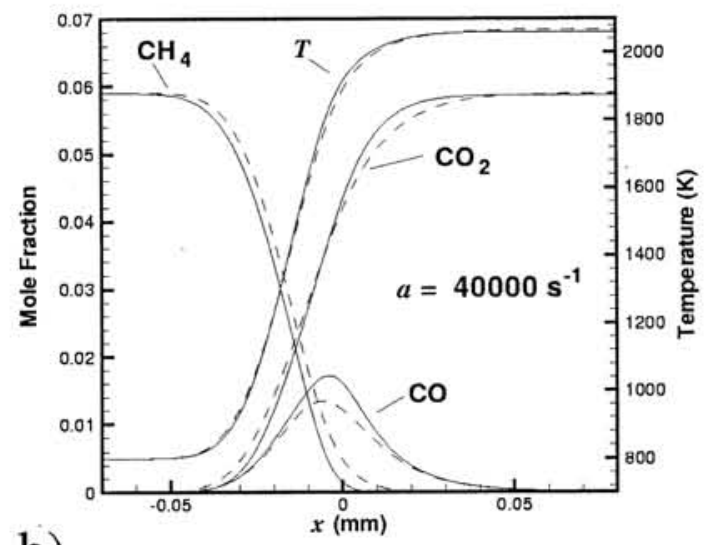

b)

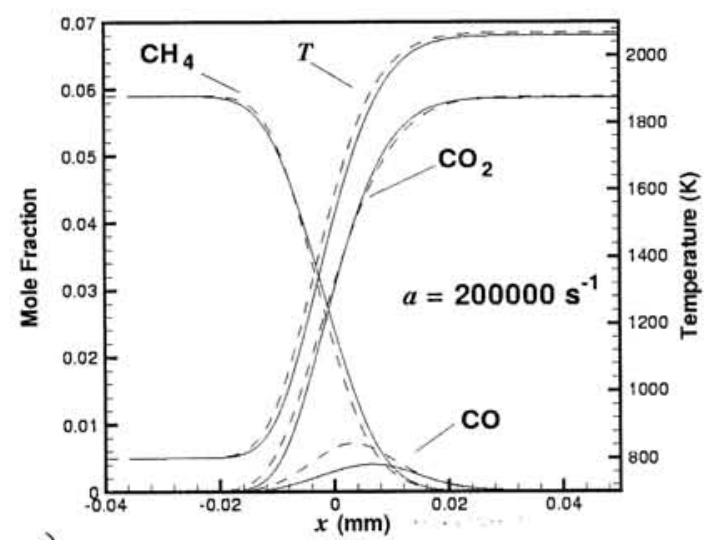

c)

Fig. 8. The profiles of main species and temperature across the counterflow mixing layer with $p=18$ bar as obtained with detailed chemistry (solid lines) and with the reduced kinetics (dashed lines) for an adiabatic flame with reactantside equivalence ratio and temperature $\phi=0.6$ and $T_{u}=$ $800 \mathrm{~K}$. strained flame of this type is seen, for instance, in Fig. 8a. The resulting flame structure is that of a freely propagating flame, as revealed by comparing the profiles in Fig. 8a with those given previously in Fig. 4a. As can be seen in Fig. $8 \mathrm{~b}$ and $\mathrm{c}$, for increasing values of $a$ the flame moves closer to the stagnation plane, and eventually migrates to the products side of the mixing layer in this adiabatic case.

The mutual comparison of the solid and dashed profiles shown in Fig. 8 indicates that the reduced kinetics accurately describes the effects of strain on flame structure. For instance, significant errors in $\mathrm{CO}$ profiles are only found for the largest value of the strain rate considered. The accuracy of the description extends also to the $\mathrm{H}_{2}-\mathrm{O}_{2}$ radical pool, as can be seen in Fig. 9, where profiles of $\mathrm{OH}, \mathrm{O}$, and $\mathrm{H}$ radicals corresponding to the intermediate case $a=40,000 \mathrm{~s}^{-1}$ are given. Even for this case of relatively large strain, the inaccuracies found in peak mol fractions and in profile shapes are comparable to those previously observed in Fig. 5 for the unstrained case.

\section{Overall Consumption Rates}

The global effect of stretch on the flame can be adequately measured through the so-called reaction-rate ratios [17]. These are functions of the strain rate that are defined as the ratio of the integrated reaction rate to the corresponding value for a freely propagating flame. Thus, the fuel-consumption and $\mathrm{CO}_{2}$ production ratios are given by

$$
m_{\mathrm{F}}=\frac{\int_{-\infty}^{\infty} \omega_{\mathrm{F}} d x}{\left(\int_{-\infty}^{\infty} \omega_{\mathrm{F}} d x\right)_{a=0}}
$$

and

$$
m_{\mathrm{CO}_{2}}=\frac{\int_{-\infty}^{\infty} \omega_{\mathrm{CO}_{2}} d x}{\left(\int_{-\infty}^{\infty} \omega_{\mathrm{CO}_{2}} d x\right)_{a=0}},
$$



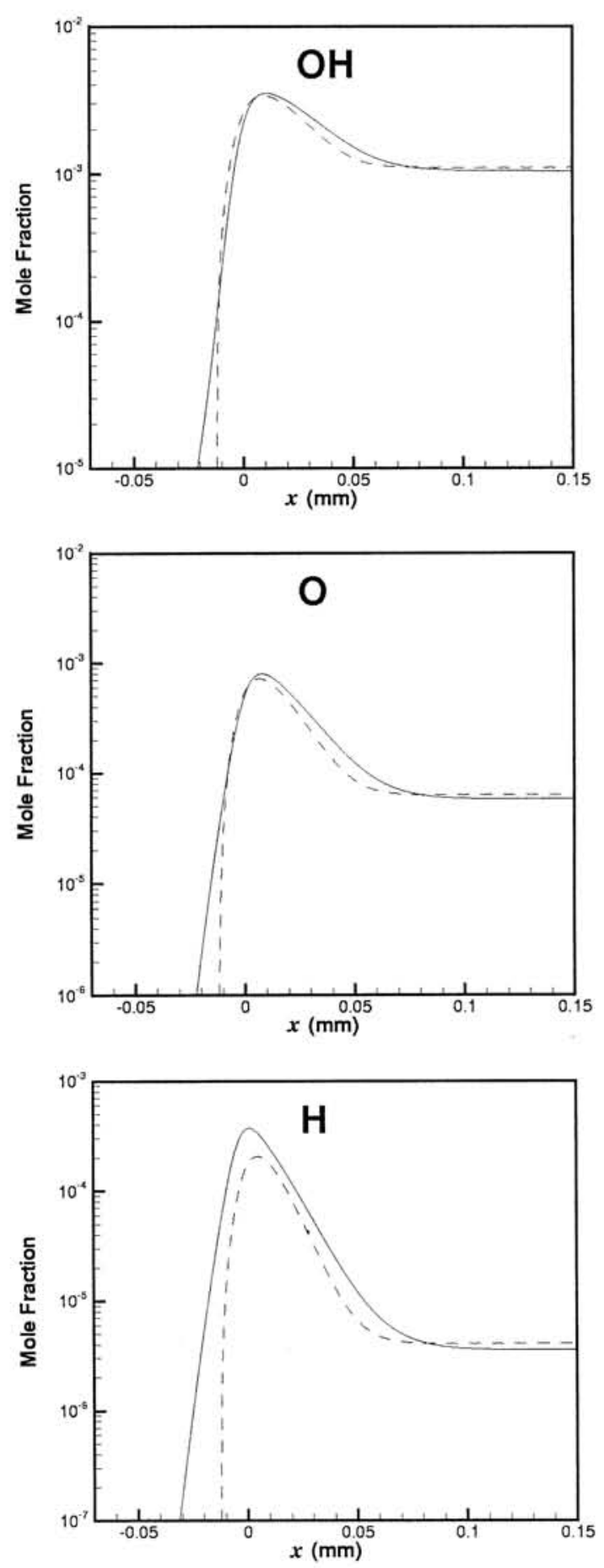

Fig. 9. The variation of $\mathrm{OH}, \mathrm{O}$, and $\mathrm{H}$ across the counterflow mixing layer with $p=18$ and $a=40,000 \mathrm{~s}^{-1}$ as obtained with detailed chemistry (solid lines) and with the reduced kinetics (dashed lines) for an adiabatic flame with $p=18$ bar, $\phi=0.6$ and $T_{u}=800 \mathrm{~K}$.

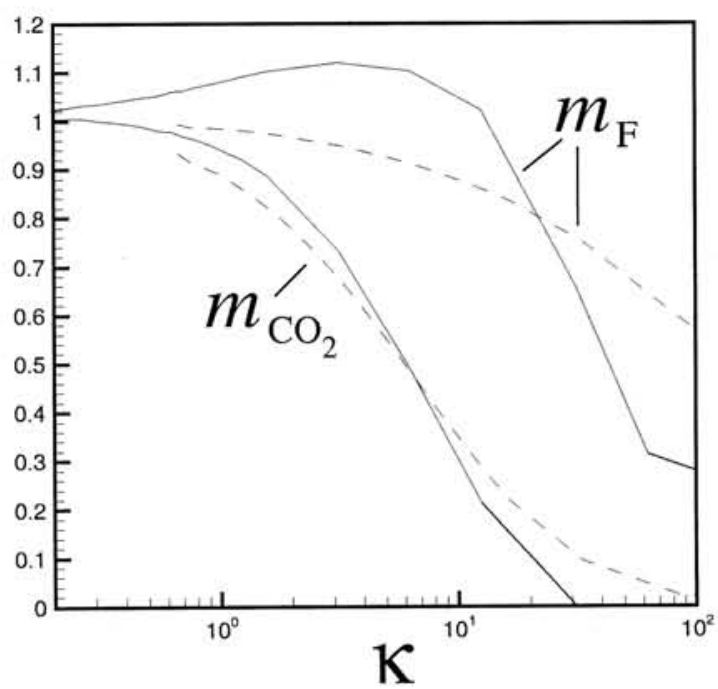

Fig. 10. The variation of the fuel-consumption and $\mathrm{CO}_{2}$ production ratios with the Karlowitz number $\kappa=a D_{T} / u_{l}^{2}$ as obtained with detailed chemistry (solid lines) and with the reduced kinetics (dashed lines) for an adiabatic flame with $p=18$ bar, $T_{u}=800 \mathrm{~K}$, and $\phi=0.6$.

where $\omega_{\mathrm{F}}$ and $\omega_{\mathrm{CO}_{2}}$ represent the local rates of fuel consumption and $\mathrm{CO}_{2}$ production (mol per unit volume per unit time). The variation of these two quantities with strain for the adiabatic flame shown in Fig. 8 is given in Fig. 10. As before, solid lines represent results of detailedchemistry calculations, and dashed lines are the results of the two-step reduced kinetics. For the latter calculations $\omega_{\mathrm{F}}=\omega_{\mathrm{I}}$ and $\omega_{\mathrm{CO}_{2}}=\omega_{\mathrm{II}}$, as follows from the overall steps I and II, while a number of elementary steps from Appendix A are involved in the detailed-chemistry rates, namely, $\omega_{\mathrm{F}}=-\omega_{25}-\omega_{30}+\omega_{34}+\omega_{35}+\omega_{36}$ and $\omega_{\mathrm{CO}_{2}}=\omega_{17}+\omega_{22}$.

The results indicate that the amount of $\mathrm{CO}_{2}$ generated per unit flame surface decreases with strain, with significant decreases already occurring for values of $\kappa$ of order unity (for instance, $m_{\mathrm{CO}_{2}}=0.5$ for $\kappa \simeq 5$ ). The fuel burning rate is less affected by strain; the value of $m_{\mathrm{F}}$, although increases initially, remains roughly equal to unity for $\kappa \leqslant 20$. This distinct behavior, also observed in previous numerical studies [4], follows from the disparity in chemical times previously seen: $\mathrm{CO}_{2}$ production by $\mathrm{CO}$ oxidation is a relatively slow process that takes place in thick regions that are easily affected by strain, while fuel consumption is fast, and occurs in thin 


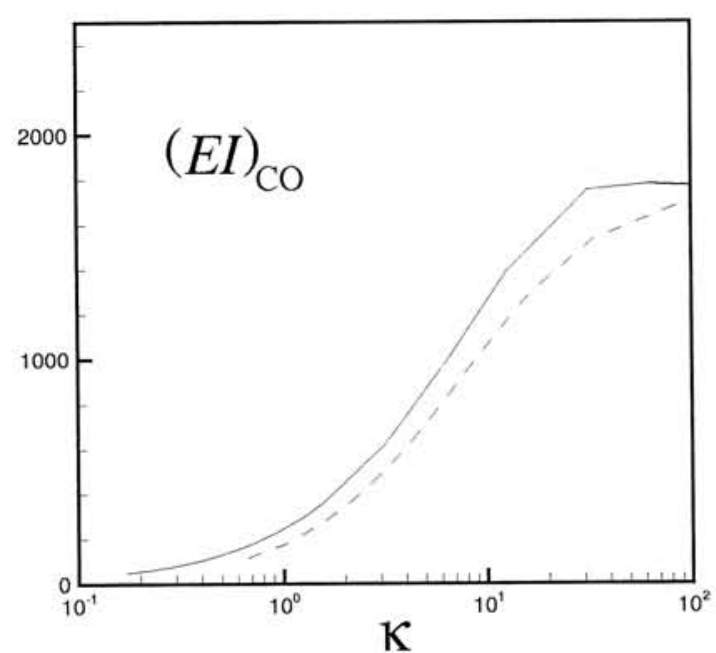

Fig. 11. The variation of $\mathrm{CO}$ emission index with the Karlowitz number as obtained with detailed chemistry (solid lines) and with the reduced kinetics (dashed lines) for an adiabatic flame with $p=18 \mathrm{bar}, T_{u}=800 \mathrm{~K}$, and $\phi=0.6$.

layers that are only perturbed under strong strain.

Implications about $\mathrm{CO}$ emissions can be withdrawn from these results. For moderate strains, Fig. 10 reveals that flame stretch leads to a severe reduction in the rate at which $\mathrm{CO}$ is oxidized, while the rate of $\mathrm{CO}$ production by fuel oxidation remains roughly at the same level. The difference $\int_{-\infty}^{\infty} \omega_{\mathrm{F}} d x-\int_{-\infty}^{\infty} \omega_{\mathrm{CO}_{2}} d x$, which is the rate of $\mathrm{CO}$ emission per unit flame surface, therefore becomes an increasing function of the strain rate. An appropriate representation for this quantity is the emission index

$(E I)_{\mathrm{CO}}=\frac{W_{\mathrm{CO}}}{W_{\mathrm{CH}_{4}}}\left(1-\frac{\int_{-\infty}^{\infty} \omega_{\mathrm{CO}_{2}} d x}{\int_{-\infty}^{\infty} \omega_{\mathrm{F}} d x}\right) \times 10^{3}$,

defined as the grams of $\mathrm{CO}$ emitted per kilogram of fuel consumed, with $W_{i}$ representing the molecular weight of species $i$. The variation of this quantity with strain can be obtained by straightforward manipulation of the data in Fig. 10 to give the results included for completeness in Fig. 11. As can be seen, for values of $\kappa$ of order unity, a significant amount of the fuel burnt is emitted from the flame as CO. Clearly, to avoid unacceptable emission levels in gasturbine operation, the $\mathrm{CO}$ that is locally emitted from the stretched flamelets must be burnt elsewhere in the combustor. Predictions of $\mathrm{CO}$ emissions, therefore, require the numerical computation of the whole reactive flow field, a task that is facilitated by the simplified formulation presented in the following section.

As can be seen in Figs. 10 and 11, the reduced kinetics describes the overall response to strain with reasonably good accuracy. In particular, the decrease in $\mathrm{CO}_{2}$ production rate with the Karlowitz number is reproduced with errors smaller than $10 \%$ over two orders of magnitude in strain rate, a level of accuracy that could be expected in view of the previous comparisons of CO profiles shown in Figs. 4, 5, and 8. Somewhat larger discrepancies are found in the prediction of the fuel-consumption rate, with errors being typically smaller than $20 \%$ for $\kappa \leqslant 50$. In particular, with the value of $T_{a}$ selected for the approximate Arrhenius law in Eq. 15, the reduced kinetics is not able to predict the initial increase in $m_{\mathrm{F}}$ seen in the detailed-chemistry calculations, where a maximum value $m_{\mathrm{F}} \simeq 1.1$ is reached for $\kappa \simeq 3$. Although augmenting $T_{a}$ improves the description of $m_{\mathrm{F}}$ by yielding this initial increase, the resulting calculation becomes increasingly stiffer, so that the associated small improvement in $m_{\mathrm{F}}$ does not seem to justify the use of a larger $T_{a}$.

\section{Nonadiabatic Flames}

Secondary air is provided for dilution in typical combustion chambers. Entrainment of this colder gas reduces the temperature of the hot recirculating products, with additional heat losses emerging through radiation. To study how this reduced temperature may affect stretched flames, we consider the fresh-to-burnt configuration previously calculated $(p=18$ bar, $T_{u}=800 \mathrm{~K}, \phi=0.6$ ), but with a modified burnt-side temperature $T_{b}=1500 \mathrm{~K}$. Profiles of temperature, main species, and radicals corresponding to a strain rate $a=5000 \mathrm{~s}^{-1}(\kappa=$ 0.83 ) are presented in Fig. 12, showing how the accuracy of the reduced kinetics extends to the description of nonadiabatic flames. The increasing departures seen as the radical concentrations decrease to small values on both sides of 

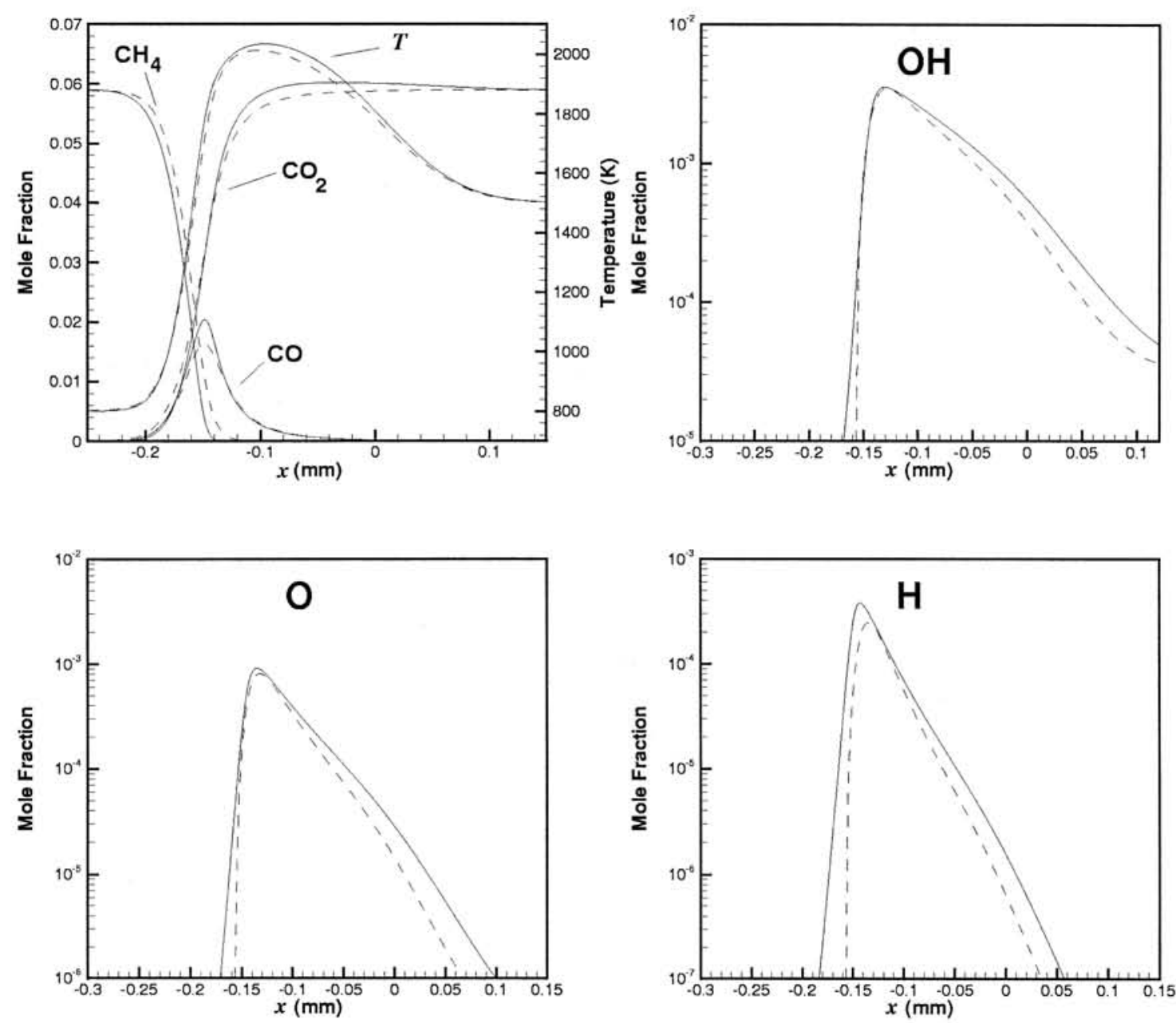

Fig. 12. The profiles of main species, temperature, and radicals across the counterflow mixing layer with $p=18$ bar and $a=$ $5000 \mathrm{~s}^{-1}$ as obtained with detailed chemistry (solid lines) and with the reduced kinetics (dashed lines) for an adiabatic flame with burnt temperature $T_{b}=1500 \mathrm{~K}$ and with reactant-side equivalence ratio and temperature $\phi=0.6$ and $T_{u}=800 \mathrm{~K}$.

the mixing layer are attributable to the simplificed transport description utilized in the reduced-kinetic calculations.

Increasing values of $a$ were seen in Fig. 8 to cause the adiabatic flame to migrate towards the hot side of the mixing layer. Although an initial increase in fuel-consumption rate was observed in Fig. 10, for larger values of $\kappa$ the resulting flame was increasingly weak, with reaction-rate ratios continuously decreasing towards a zero value. This continuous dependence on the strain rate is no longer observed in nonadiabatic flames when the temperature of the products is sufficiently low, as can be seen in Fig. 13, where the variation of $m_{\mathrm{F}}$ and $m_{\mathrm{CO}_{2}}$ with strain rate is exhibited. As in Fig. $10, \mathrm{CO}_{2}$ production is seen to decrease faster than fuel consumption, and also values of $m_{\mathrm{F}}$ larger than unity appear for moderate strains. However, as the Karlowitz number increases sufficiently, the behavior changes drastically from that previously seen: a sharp reduction in reaction rates leads to an abrupt extinction event, so that a premixed flame cannot exist for $a$ above a critical value, $a_{c}$.

This phenomenon of premixed-flame, straininduced extinction has been addressed in a number of studies $[15,16]$. For instance, Libby and Williams [15] considered the effect of nonabiabaticity for a fresh-to-burnt configuration, with additional nonunity Lewis number effects being taken into account in a sequel [16]. A one-step Arrhenius chemistry with large nondi- 

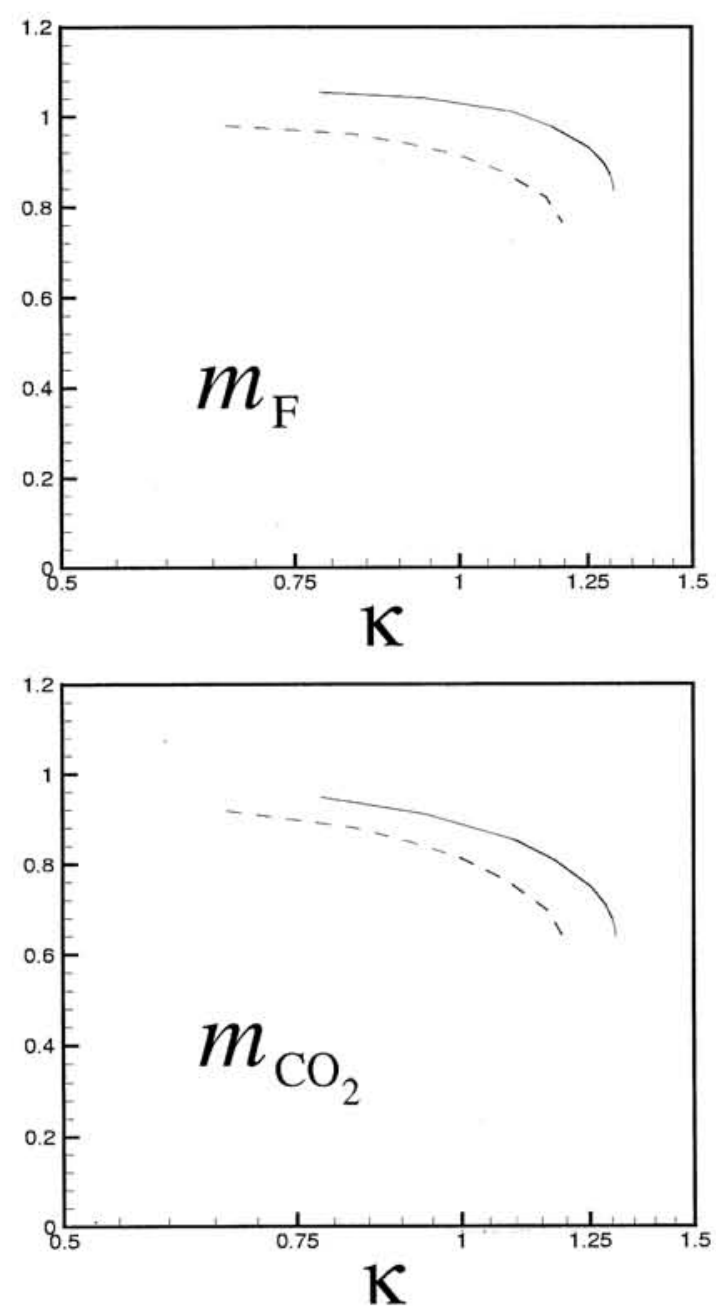

Fig. 13. The variation of the fuel-consumption and $\mathrm{CO}_{2}-$ production ratios with the Karlowitz number as obtained with detailed chemistry (solid lines) and with the reduced kinetics (dashed lines) for an adiabatic flame with $p=18$ bar, $T_{b}=1500 \mathrm{~K}, T_{u}=800 \mathrm{~K}$, and $\phi=0.6$.

mensional activation energy was employed for the chemistry description. The physical mechanism triggering extinction in nonadiabatic flames was seen to be the heat loss towards the burnt side of the mixing layer. Flame quenching was observed for strain rates high enough to cause the flame to approach the stagnation plane sufficiently to give a relative decrease in peak temperature of the order of the reciprocal of the activation energy. A similar mechanism explains the extinction of lean hydrocarbon-air flames depicted in Fig. 13. As the flame approaches the stagnation plane, an increasing amount of $\mathrm{CO}$ leaves the flame unburnt, leading to a smaller $\mathrm{CO}_{2}$ production rate and to a reduced rate of heat release. That, in turn, tends to reduce the temperature at the fuel-consumption layer in this nonadiabatic case, leading to extinction when the Karlowitz number reaches a critical value of order unity.

The results of the calculations indicate that the critical strain rate predicted by the reduced kinetics is in excellent agreement with that determined with detailed chemistry. For instance, in Fig. 13 the reduced kinetics yields $a_{c}=7200 \mathrm{~s}^{-1}$, while a critical value $a_{c}=8400 \mathrm{~s}^{-1}$ is obtained with detailed chemistry. To study the dependence of $a_{c}$ on the temperature sensitivity of the fuel-consumption rate, values of $T_{a}$ different from the reference value $T_{a}=22,850 \mathrm{~K}$ were investigated, with the corresponding value of the preexponential factor $B$ adjusted each time as previously indicated. It was found that larger values of $T_{a}$ do not modify appreciably the value of $a_{c}$. For instance, the calculations performed with $T_{a}=$ $30,000 \mathrm{~K}$ yielded $a_{c} \simeq 6700 \mathrm{~s}^{-1}$. This independence suggests that, because extinction occurs mainly through the flowfield interaction with the $\mathrm{CO}$-oxidation region, the fuel-consumption rate plays only a secondary role on the extinction phenomenon, provided the value of $T_{a}$ is large enough to ensure a thin fuel-consumption layer. On the other hand, smaller values of $T_{a}$ were seen to increase $a_{c}$, and no extinction was found for $T_{a}<16,000 \mathrm{~K}$. Clearly, although the value of $T_{a}=22,850 \mathrm{~K}$ selected here seems to be large enough, consideration of extinction phenomena introduces an additional constraint on the minimum value of $T_{a}$, a characteristic of the proposed kinetics to be kept in mind in future applications.

\section{NO Production in Stretched Flames}

The NO content that appears in the hot recirculating regions of the gas-turbine combustion chamber depends on the overall residence time available, and also on other characteristics of the combustor, including the mixing with secondary air. Clearly, for a satisfactory operation, NO levels in the combustor must be far below the values corresponding to chemical equilibrium at the adiabatic flame temperature. Therefore, in calculations of strained flames, a realistic burnt-side NO mol fraction, much smaller 

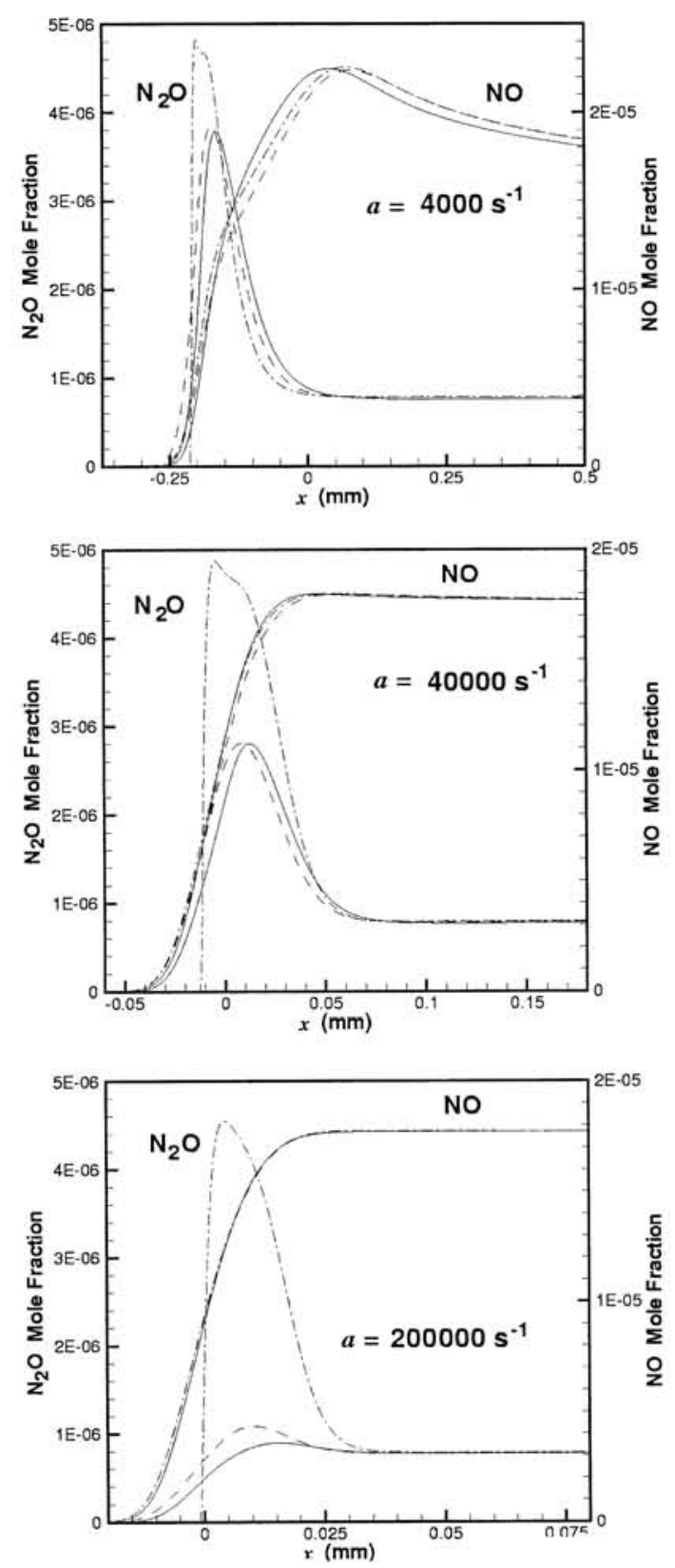

Fig. 14. The profiles $\mathrm{NO}$ and $\mathrm{N}_{2} \mathrm{O}$ mol fractions across the counterflow mixing layer with $p=18$ bar as obtained with detailed chemistry (solid lines), with the reduced kinetics (dashed lines) and with the reduced kinetics with $\mathrm{N}_{2} \mathrm{O}$ in steady state (dot-dashed lines) for an adiabatic flame with reactant-side equivalence ratio and temperature $\phi=0.6$ and $T_{u}=800 \mathrm{~K}$.

than the equilibrium value, must be specified, giving NO profiles that depend on this arbitrary choice. For instance, Fig. 14 shows profiles of
$\mathrm{NO}$ and $\mathrm{N}_{2} \mathrm{O}$ corresponding to the adiabatic flame in Fig. 8 with a mol fraction of $\mathrm{NO}$ equal to $1.78 \times 10^{-5}$ selected for the products stream. As can be inferred from the results in Fig. 6, this value corresponds roughly to the NO level achieved in the postflame region after a residence time of $10^{-3} \mathrm{~s}$. As in Fig. 6, solid lines represent results of detailed chemistry, and the reduced chemistry calculations are performed with the two-step nitrogen chemistry (dashed lines) and also with the one-step description with $\mathrm{N}_{2} \mathrm{O}$ in steady state (dot-dashed lines).

Despite the arbitrariness in the NO profiles previously mentioned, the results in Fig. 14 serve to demonstrate the level of accuracy of the reduced NO chemistry. Thus, when two steps are used for NO production, the results are in close agreement with those of detailed chemistry in the range of strain rates investigated. The steady-state assumption for $\mathrm{N}_{2} \mathrm{O}$, on the other hand, is seen to fail at moderate strains, with departures in $\mathrm{N}_{2} \mathrm{O}$ profiles increasing with strain. Note that, because of the boundary condition for NO at $x=\infty$, these inaccuracies do not translate into noticeable errors in NO profiles.

As previously mentioned in relation to the results of freely propagating flames, two different regions of NO production can be identified. There exists a rapid production rate associated with the superequilibrium radical concentrations that appear at the flame front. This "prompt" NO is followed by a constant NO production rate $\left(\omega_{\mathrm{NO}}\right)_{b}$ that occurs everywhere in the equilibrium region. Because the latter only depends on the equilibrium temperature and equilibrium radical concentrations, it is always present on the product side of stretched flames regardless of the level of strain rate imposed. Prompt NO, on the other hand, is affected by flame stretch through the modified radical pool. In trying to evaluate this particular effect, an appropriate measure for the rate of prompt NO production per unit flame surface must be introduced. One such measure, that isolates the effect of prompt NO by subtracting the equilibrium production, is given by $\int_{-\infty}^{\infty} \omega_{\mathrm{NO}} d x-$ $\int_{x_{o}}^{\infty}\left(\omega_{\mathrm{NO}}\right)_{b} d x$, where $x_{o}$ is the location of the flame, defined as before where $\mathrm{CO}$ reaches its peak value. To plot in Fig. 15 the variation of this 


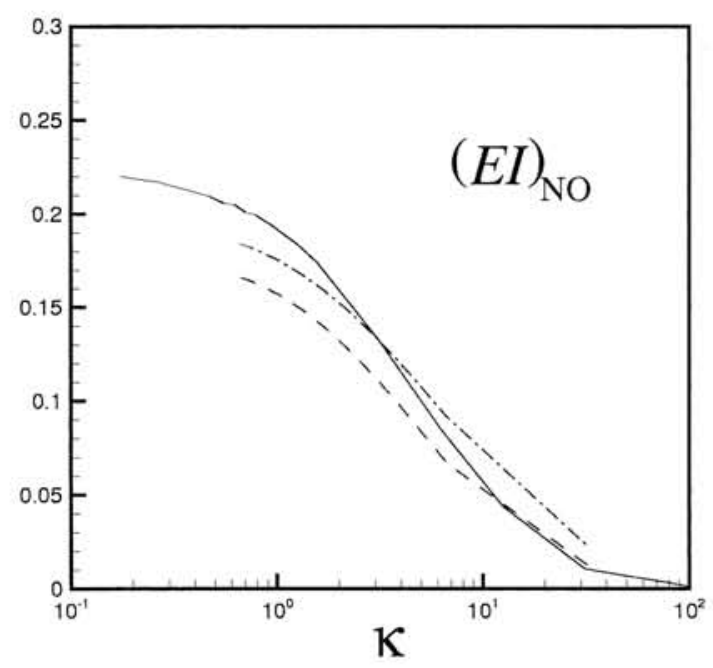

Fig. 15. The variation of the prompt NO emission index with the Karlowitz number as obtained with detailed chemistry (solid lines), with the reduced kinetics (dashed lines) and with the reduced kinetics with $\mathrm{N}_{2} \mathrm{O}$ in steady state (dot-dashed lines) for an adiabatic flame with $p=18$ bar, $T_{u}=800 \mathrm{~K}$, and $\phi=0.6$.

quantity with strain, use is made of the emission index

$$
\begin{aligned}
& (E I)_{\mathrm{NO}}=\frac{W_{\mathrm{NO}}}{W_{\mathrm{CH}_{4}}} \\
& \left(\frac{\int_{-\infty}^{\infty} \omega_{\mathrm{NO}} d x-\int_{x_{o}}^{\infty}\left(\omega_{\mathrm{NO}}\right)_{b} d x}{\int_{-\infty}^{\infty} \omega_{\mathrm{F}} d x}\right) \times 10^{3},
\end{aligned}
$$

defined as the grams of NO produced at the flame front per kilogram of fuel burnt. As can be seen, the reduced kinetics yields results in good agreement with those of detailed chemistry, and only small differences are found between the two reduced description.

\section{SIMPLIFIED FORMULATION}

The reduced kinetics developed above is designed to describe combustion in lean premixed combustion chambers, enabling in particular the computation of $\mathrm{CO}$ and NO emissions. The results presented above indicate that two overall steps for fuel oxidation, supplemented by one overall step for NO production, provide sufficient accuracy under most conditions. The associated numerical calculation of the flow field in the combustor requires the integration of the conservation equations for chemical species and energy, along with the continuity and momentum equations. In general, a model for turbulent transport must be incorporated to the conservation equations.

As a preliminary step to enable computations with the reduced kinetics proposed, we rewrite here the species and energy conservation equations in a simplified form that can be used as a starting point in modeling studies. In particular, the selected boundary conditions will be those of a prototypical gas-turbine combustion chamber. Thus, we consider a main feed stream that supplies a mixture of fuel and air, together with secondary feed streams that provide air to dilute the combustion products. As previously mentioned in the Introduction, we assume unity Lewis numbers for all of the chemical species that remain out of steady state (a very good approximation in view of the laminar flame calculations previously shown), and define a convective-diffusive differential operator

$$
L()=\frac{\partial}{\partial t}[\rho()]+\nabla \cdot[\rho \bar{v}()]-\nabla \cdot\left[\rho D_{T} \nabla()\right],
$$

where $\rho$ represents the density, $\bar{v}$ is the flow velocity and $D_{T}=\lambda /\left(\rho c_{p}\right)$ denotes the thermal diffusivity of the gas mixture, with $\lambda$ and $c_{p}$ representing its thermal conductivity and specific heat at constant pressure. In terms of this operator, the conservation equations for the reactive species corresponding to the reduced chemistry description I-II can be written as

$$
\begin{aligned}
& L\left(\Gamma_{\mathrm{CH}_{4}}\right)=-\omega_{\mathrm{I}}, \\
& L\left(\Gamma_{\mathrm{CO}}\right)=\omega_{\mathrm{I}}-\omega_{\mathrm{II}}, \\
& L\left(\Gamma_{\mathrm{CO}_{2}}\right)=\omega_{\mathrm{II}}, \\
& L\left(\Gamma_{\mathrm{H}_{2} \mathrm{O}}\right)=2 \omega_{\mathrm{I}}, \\
& L\left(\Gamma_{\mathrm{O}_{2}}\right)=-\frac{3}{2} \omega_{1}-\frac{1}{2} \omega_{\mathrm{II}},
\end{aligned}
$$

where use is made of the variables $\Gamma_{i}=Y_{i} / W_{i}=$ $[i] / \rho$, with $Y_{i}$ denoting the mass fraction of chemical species $i$. To also describe NO produc- 
tion, the above equations must be supplemented with

$$
L\left(\Gamma_{\mathrm{NO}}\right)=2 \omega_{\mathrm{NI}}
$$

as follows from the one-step nitrogen chemistry description, with the concentration of nitrous oxide being calculated in this approximation from the steady-state expression given in Eq. 20. Note that the concentration of $\mathrm{N}_{2}$, necessary to evaluate the rate of reaction NI, can be either computed from the condition $\Sigma_{i} W_{i} \Gamma_{i}=1$, or calculated by integrating the transport equation

$L\left(\Gamma_{\mathbf{N}_{2}}\right)=0$.

Similarly, the energy equation can be written for the thermal enthalpy $h_{T}=\int^{T} c_{p} d T$ as

$$
L\left(h_{T}\right)=q_{\mathrm{I}} \omega_{\mathrm{I}}+q_{\mathrm{II}} \omega_{\mathrm{II}}-\nabla \cdot \bar{q}_{\mathrm{R}},
$$

where the overall heats of reaction are related to the enthalpies of formation per mol of species $i, h_{i}^{o}$, by the equations $q_{\mathrm{I}}=h_{\mathrm{CO}}^{o}+2 h_{\mathrm{H}_{2} \mathrm{O}}^{o}$ $-h_{\mathrm{CH}_{4}}^{o} \simeq 124,250 \mathrm{cal} / \mathrm{mol}$, and $q_{\mathrm{II}}=h_{\mathrm{CO}_{2}}^{o}-$ $h_{\mathrm{CO}}^{o}=67,700 \mathrm{cal} / \mathrm{mol}$. In the formulation, $\nabla \cdot \bar{q}_{R}$ represents the radiative heat loss per unit volume. In writing Eq. 33, a low-Mach-number approximation has been employed, and unsteady pressure variations have been neglected. To completely describe the reacting flow field, Eqs. 26-33 must be integrated together with the continuity and momentum equations with appropriate boundary and initial conditions.

Because of partial mixing between the fuel and the air, the conditions in the main feed stream are in general nonuniform, so that at the entrance of the combustor we find the reactant distributions $\Gamma_{\mathrm{CH}_{4}}=\Gamma_{\mathrm{CH}_{4} e}$, and $\Gamma_{\mathrm{O}_{2}}=\Gamma_{\mathrm{O}_{2} e}$ together with the nitrogen distribution $\Gamma_{\mathrm{N}_{2}}=$ $\Gamma_{N_{2} e}$ and the thermal-enthalpy distribution $h_{T}=$ $h_{T e}$. If methane and air are used in generating the reactant mixture, then the local values of $\Gamma_{\mathrm{CH}_{4} e}, \Gamma_{\mathrm{O}_{2} e}$, and $\Gamma_{\mathrm{N}_{2} e}$ are related to the local equivalence ratio $\phi_{e}$ by the equations

$$
\begin{aligned}
\frac{\Gamma_{\mathrm{CH}_{4} e}}{W_{\mathrm{CH}_{4}}^{-1}} & =1-\frac{\Gamma_{\mathrm{O}_{2} e}}{\Gamma_{\mathrm{O}_{2} a}}=1-\frac{\Gamma_{\mathrm{N}_{2} e}}{\Gamma_{\mathrm{N}_{2} a}} \\
& =\frac{\phi_{e}}{\phi_{e}+2 /\left(W_{\mathrm{CH}_{4}} \Gamma_{\mathrm{O}_{2} a}\right)}
\end{aligned}
$$

where $\Gamma_{\mathrm{O}_{2} a} \simeq 0.23 / W_{\mathrm{O}_{2}}$ and $\Gamma_{\mathrm{N}_{2} a} \simeq 0.77 / W_{\mathrm{N}_{2}}$ are the values of the functions $\Gamma_{\mathrm{O}_{2}}$ and $\Gamma_{\mathrm{N}_{2}}$ in air. On the other hand, in the secondary feed streams, $\Gamma_{\mathrm{O}_{2}}=\Gamma_{\mathrm{O}_{2} a}, \Gamma_{\mathrm{N}_{2}}=\Gamma_{\mathrm{N}_{2} a}, \Gamma_{\mathrm{CH}_{4}}=0$ and $h_{T}=h_{T a}$. Also, appropriate boundary conditions in all streams are $\Gamma_{\mathrm{H}_{2} \mathrm{O}}=\Gamma_{\mathrm{CO}_{2}}=\Gamma_{\mathrm{CO}}=$ $\Gamma_{\mathrm{NO}}=0$. At the walls of the combustor, the nonpermeability condition yields $\nabla \Gamma_{i} \cdot \bar{n}=0$ as the appropriate boundary condition for all species, where $\bar{n}$ is the unit vector normal to the wall. The boundary condition for the thermal enthalpy at the walls is in general more complicated, and may require the detailed consideration of the heat conduction problem in the wall. In particular, the simple boundary condition $\nabla h_{T} \cdot \bar{n}=0$ applies when the walls can be assumed to be adiabatic, while the assumption of isothermal walls leads to the constant boundary condition $h_{T}=h_{T w}$.

In view of the above boundary conditions for $\mathrm{CO}$ and products, a first step to simplify the integration of Eqs. 26-33 follows from combining linearly Eqs. 27-29 to give

$L\left(\Gamma_{\mathrm{CO}}+\Gamma_{\mathrm{CO}_{2}}-\frac{1}{2} \Gamma_{\mathrm{H}_{2} \mathrm{O}}\right)=0$,

an equation that can be readily integrated with the previously mentioned boundary conditions to yield

$\Gamma_{\mathrm{H}_{2} \mathrm{O}}=2\left(\Gamma_{\mathrm{CO}}+\Gamma_{\mathrm{CO}_{2}}\right)$.

On the other hand, introducing the coupling functions

$$
\begin{aligned}
X & =\frac{\Gamma_{\mathrm{CH}_{4}}+\Gamma_{\mathrm{CO}}+\Gamma_{\mathrm{CO}_{2}}}{W_{\mathrm{CH}_{4}}^{-1}} \\
& =\frac{\Gamma_{\mathrm{O}_{2} a}-\Gamma_{\mathrm{O}_{2}}-\frac{3}{2} \Gamma_{\mathrm{CO}}-2 \Gamma_{\mathrm{CO}_{2}}}{\Gamma_{\mathrm{O}_{2} a}} \\
& =\frac{\Gamma_{\mathrm{N}_{2} a}-\Gamma_{\mathrm{N}_{2}}}{\Gamma_{\mathrm{N}_{2} a}}
\end{aligned}
$$

and

$H=\frac{h_{T}-h_{T a}-q_{\mathrm{I}} \Gamma_{\mathrm{CO}}-\left(q_{\mathrm{I}}+q_{\mathrm{II}}\right) \Gamma_{\mathrm{CO}_{2}}}{h_{T a}}$

reduces the problem to that of integrating

$L\left(\Gamma_{\mathrm{CH}_{4}}\right)=-\omega_{\mathrm{I}}$,

$L\left(\Gamma_{\mathrm{CO}_{2}}\right)=\omega_{\mathrm{II}}$,

$L(X)=0$, 
$L(H)=-\nabla \cdot \bar{q}_{R}$,

$L\left(\Gamma_{\mathrm{NO}}\right)=2 \omega_{\mathrm{NI}}$

with boundary conditions $\Gamma_{\mathrm{CH}_{4}} W_{\mathrm{CH}_{4}}=X=$ $\phi_{e} /\left[\phi_{e}+2 /\left(W_{\mathrm{CH}_{4}} \Gamma_{\mathrm{O}_{2} a}\right)\right], \Gamma_{\mathrm{CO}_{2}}=\Gamma_{\mathrm{NO}}=0$, and $H=H_{e}=\left(h_{T e}-h_{T a}\right) / h_{T a}$ in the main feed stream, and $\Gamma_{\mathrm{CH}_{4}}=\Gamma_{\mathrm{CO}_{2}}=\Gamma_{\mathrm{NO}}=X=H=0$ in the secondary feed streams. At the walls, the variable $X$ satisfies $\nabla X \cdot \bar{n}=0$, while the boundary condition for $H$ is more complicated, reducing to $\nabla H \cdot \bar{n}=0$ when adiabatic walls are considered and to $H=\left[\left(h_{T w}-h_{T a}\right)-\right.$ $\left.q_{\mathrm{I}}\left(X / W_{\mathrm{CH}_{4}}-\Gamma_{\mathrm{CH}_{4}}\right)-q_{\mathrm{II}} \Gamma_{\mathrm{CO}_{2}}\right] / h_{T a}$ in the case of isothermal walls. Note that the definition of $X$ shown in Eq. 37 is motivated by the relationship between the fuel and air content in the feed stream displayed in Eq. 34.

In the particular case of perfect mixing, the boundary conditions for $X$ and $H$ in the main stream reduce to constant values that can be used to redefine normalized variables $\bar{X}=X / X_{e}$ and $\bar{H}=H / H_{e}$, so that $\bar{X}=\bar{H}=1$ in the main stream. A further simplification arises when adiabatic walls are considered and radiation is neglected, a case for which Eq. 43 can be replaced by $H=H_{e} X / X_{e}$, which in turn reduces to $H=0$ if $h_{T e}=h_{T a}$.

Note that, although with the transport operator $L($ ) defined in Eq. 25 the conservation Eqs. 39-43 can be readily used for direct numerical simulation of laminar or turbulent flows, these compact equations and their associated boundary conditions also constitute an appropriate basis for modeling studies of turbulent 3D flows, but such modeling equations are not further elaborated here.

\section{CONCLUSIONS}

The approximation of slow $\mathrm{CO}$ oxidation has been used to derive a reduced chemical kinetic mechanism for the premixed combustion of fuel-lean methane-air mixtures at elevated pressures. It is seen that, under those flowfield conditions, the fuel is oxidized rapidly in a thin layer, producing as a result water vapor and $\mathrm{CO}$. The latter is then slowly oxidized to $\mathrm{CO}_{2}$ in a much larger region, where all intermediates but $\mathrm{CO}$ follow a steady-state approximation. Use of the associated steady-state expressions for hydrogen and radicals enables the resulting rate of
$\mathrm{CO}$ oxidation to be expressed in terms of the temperature, pressure, and of the concentrations of $\mathrm{CO}, \mathrm{O}_{2}, \mathrm{CO}_{2}$, and $\mathrm{H}_{2} \mathrm{O}$. In the fuelconsumption layer, on the other hand, the steady-state assumptions for hydrogen and radicals fail. This complicating characteristic is overcome in the model by introducing a heuristic law for the rate of fuel consumption that accommodates semiempirically fitted dependences on reactant mass fractions, temperature, and pressure. The two-step fuel-oxidation chemistry is supplemented with a one-step mechanism for NO production that accounts for both the thermal and the nitrous-oxide paths. Calculations of one-dimensional laminar flames with the resulting three-step mechanism revealed that the reduced kinetics is able to predict with remarkable accuracy the main characteristics of fuel-lean premixed combustion, including in particular flame propagation velocities, flame structures, strain-induced extinction, and emissions of $\mathrm{CO}$ and NO.

It is worth emphasizing here that the range of applicability of the proposed reduced-chemistry mechanism is limited to fuel-lean $(\phi \lesssim 1)$ premixed combustion at elevated pressure $(p \geq$ 5 bar) and elevated initial temperature $\left(T_{u} \gtrsim\right.$ $500 \mathrm{~K}$ ). The specific selection of the reactionrate parameters of the fuel-oxidation rate given in Eq. 15 is linked to these combustion conditions, and is not expected to yield accurate results under different conditions of composition, pressure, and initial temperature. Furthermore, many of the assumptions underlying the present simplified description would fail should the mechanism be used outside the abovementioned range of validity. For instance, the steady-state assumption for $\mathrm{H}_{2}$ is expected to become less accurate as the pressure decreases towards atmospheric conditions, because threebody recombinations would no longer guarantee a fast $\mathrm{H}_{2}$ oxidation rate. Also, the $\mathrm{C}_{2}$ chain of fuel oxidation would become significant for rich flames, necessarily promoting NO production through the Fenimore mechanism, which was neglected in our analysis.

With $\mathrm{CO}$ oxidation being always the slowest fuel-oxidation process in high-pressure fuellean flames, it can be anticipated that the fueloxidation and NO-production chemistry of other hydrocarbon fuels be described with a 
similar three-step reduced mechanism, differences between different fuels entering only in the rate of fuel consumption. In general, for higher hydrocarbons the sequence of chemical processes leading to fuel conversion into $\mathrm{CO}$ becomes more complex than that of methane, and requires a larger number of steps for its detailed description. In seeking a simplified kinetics, however, all of these chemical processes can be globally represented by the reaction

$$
C_{x} H_{y}+\left(\frac{x}{2}+\frac{y}{4}\right) \mathrm{O}_{2} \rightarrow x \mathrm{CO}+\frac{y}{2} \mathrm{H}_{2} \mathrm{O},
$$

with concentrations of intermediates other than $\mathrm{CO}$ assumed to be negligibly small. On the other hand, all of the fuel is depleted in lean combustion at the fuel-consumption layer, and no significant differences in composition or chemical activity are found in the CO-oxidation regions of different hydrocarbon fuels. Therefore, the fuel-consumption step given in $\mathrm{Eq} .44$ together with the overall reactions

$\mathrm{CO}+\frac{1}{2} \mathrm{O}_{2} \stackrel{\mathrm{II}}{\rightleftharpoons} \mathrm{CO}_{2}$

and

$\mathrm{N}_{2}+\mathrm{O}_{2} \stackrel{\mathrm{NI}}{\rightleftharpoons} 2 \mathrm{NO}$

conform the needed reduced mechanism for a general hydrocarbon fuel. Correspondingly, a simplified formulation for the conservation equations, similar to that presented in the previous section, could be easily derived for a given hydrocarbon, modifications stemming mainly from differences in stoichiometry of the fuelconsumption step. While the rates of reactions II and NI are those derived in this paper, the reaction-rate parameters of the fuel-consumption step should be adjusted for each fuel to match the flame propagation velocity under varying conditions of pressure, composition and initial temperature, as done above for methane. Although Eq. 15 proved to be sufficient for methane oxidation, other functional forms may be needed for the fuel-consumption rate of more complex hydrocarbons.
The work reported here was supported by the European Comission under Contract BRPRCT95-0122 LOWNOX III. Partial support from the Spanish CICYT under contract No. PB940400 and from INTA under contract No. INTA 4070-0036/1995 is also acknowledged.

\section{REFERENCES}

1. Peters, N., and Williams, F. A., Combust. Flame 68: 185-207 (1987).

2. Seshadri, K., and Peters, N., Combust. Flame 73:23-44 (1988).

3. Peters, N., and Rogg, B., Reduced Kinetic Mechanisms for Applications in Combustion Systems, Lecture Notes in Physics m15, Springer-Verlag, Berlin, 1993.

4. Gauducheau, J. L., Denet, B., and Searby, G., Combust. Sci. Technol. 137:81-99 (1998).

5. Bui-Pham, M., Seshadri, K., and Williams, F. A., Combust. Flame 89:343-362 (1992).

6. Li, S. C., Williams, F. A., and Gebert, K., Combust. Flame 119:367-373 (1999).

7. Westbrook, C. K., and Dryer, F. L., Combust. Sci. Technol. 27:31-43 (1981).

8. Swaminathan, N., and Bilger, R. W., Combust. Sci. Technol. 127:167-196 (1997).

9. Williams, F. A., in Reduced Kinetic Mechanisms and Asymptotic Approximations for Methane-Air Flames (M. Smooke, Ed.), Lecture Notes in Physics, SpringerVerlag, Berlin, 1991, pp. 68-85.

10. Narayan, S., and Rajan, S., Combust. Sci. Technol. 139:159-171 (1998).

11. Baulch, D. L., Cobos, C. J., Cox, R. A., Frank, P., Hayman, G., Just, Th., Kerr, J. A., Murrells, T., Pilling, M. J., Troe, J., Walker, R. W., and Warnatz, J., Combust. Flame 98:59-79 (1994).

12. Pitsch, H., and Bollig, M., FlameMaster, A Computer Code for Homogeneous and One-Dimensional Laminar Flame Calculations, Institut für Technische Mechanik, RWTH-Aachen, 1994.

13. Hewson, J., and Bollig, M., Twenty-Sixth Symposium (Intemational) on Combustion, The Combustion Institute, Pittsburgh, PA, 1996, pp. 2171-2179.

14. Liñán, A., Bollig, M., Sánchez, A. L., and Lázaro, B., Reduced Kinetic Mechanisms for Modelling LPP Combustion in Gas Turbines, RTO Meeting Proceedings 14, Gas Turbine Engine Combustion, Emissions and Altemative Fuels, NATO (papers presented at the Applied Vehicle Technology Panel (AVT) Symposium, Lisbon, Portugal, 12-16 October 1998).

15. Libby, P. A., and Williams, F. A., Combust. Sci. Technol. 31:1-42 (1983).

16. Libby, P. A., Liñán, A., and Williams, F. A., Combust. Sci. Technol. 34:257-293 (1983).

17. Cant, R. S., Bray, K. N., Kostiuk, L. W., and Rogg, B., Combust. Sci. Technol. 95:261-283 (1994).

Received 15 February 2000; revised 5 June 2000; accepted 8 June 2000 


\section{APPENDIX A}

$\mathrm{CH}_{4}$ Oxidation Mechanism

\begin{tabular}{|c|c|c|c|c|}
\hline Number & Reaction & $A$ & $n$ & $E$ \\
\hline \multicolumn{5}{|c|}{$0.01 \mathrm{H}_{2}-\mathrm{O}_{2}$ React. (no $\mathrm{HO}_{2}, \mathrm{H}_{2} \mathrm{O}_{2}$ ) } \\
\hline 1f & $\mathrm{O}_{2}+\mathrm{H} \rightarrow \mathrm{OH}+\mathrm{O}$ & $9.756 \mathrm{E}+13$ & 0.00 & 62.1 \\
\hline $1 b$ & $\mathrm{OH}+\mathrm{O} \rightarrow \mathrm{O}_{2}+\mathrm{H}$ & $1.445 \mathrm{E}+13$ & 0.00 & 2.93 \\
\hline $2 \mathrm{f}$ & $\mathrm{H}_{2}+\mathrm{O} \rightarrow \mathrm{OH}+\mathrm{H}$ & $5.119 \mathrm{E}+04$ & 2.67 & 26.3 \\
\hline $2 \mathrm{~b}$ & $\mathrm{H}+\mathrm{OH} \rightarrow \mathrm{O}+\mathrm{H}_{2}$ & $2.301 \mathrm{E}+04$ & 2.67 & 18.5 \\
\hline $3 f$ & $\mathrm{H}_{2}+\mathrm{OH} \rightarrow \mathrm{H}_{2} \mathrm{O}+\mathrm{H}$ & $1.024 \mathrm{E}+08$ & 1.60 & 13.8 \\
\hline $3 b$ & $\mathrm{H}_{2} \mathrm{O}+\mathrm{H} \rightarrow \mathrm{H}_{2}+\mathrm{OH}$ & $4.517 \mathrm{E}+08$ & 1.60 & 77.1 \\
\hline $4 f$ & $2 \mathrm{OH} \rightarrow \mathrm{H}_{2} \mathrm{O}+\mathrm{O}$ & $1.506 \mathrm{E}+09$ & 1.14 & 0.42 \\
\hline $4 b$ & $\mathrm{O}+\mathrm{H}_{2} \mathrm{O} \rightarrow 2 \mathrm{OH}$ & $1.559 \mathrm{E}+10$ & 1.14 & 71.7 \\
\hline \multicolumn{5}{|c|}{0.02 Recombination Reactions } \\
\hline $5 f$ & $\mathrm{H}+\mathrm{OH}+\mathrm{M} 0 \rightarrow \mathrm{H}_{2} \mathrm{O}+\mathrm{MO}$ & $2.212 \mathrm{E}+22$ & -2.00 & 0 \\
\hline $5 b$ & $\mathrm{H}_{2} \mathrm{O}+\mathrm{M} 0 \rightarrow \mathrm{OH}+\mathrm{H}+\mathrm{M} 0$ & $3.360 \mathrm{E}+23$ & -2.00 & 498 \\
\hline \multicolumn{5}{|c|}{$0.03 \mathrm{HO}_{2}$ Formation/Consumption } \\
\hline $6 f$ & $\mathrm{H}+\mathrm{O}_{2}+\mathrm{M} 1 \rightarrow \mathrm{HO}_{2}+\mathrm{M} 1$ & $3.535 \mathrm{E}+18$ & -0.80 & 0 \\
\hline $6 \mathrm{~b}$ & $\mathrm{HO}_{2}+\mathrm{M} 1 \rightarrow \mathrm{O}_{2}+\mathrm{H}+\mathrm{M} 1$ & $5.058 \mathrm{E}+18$ & -0.80 & 196 \\
\hline 7 & $\mathrm{HO}_{2}+\mathrm{H} \rightarrow 2 \mathrm{OH}$ & $1.686 \mathrm{E}+14$ & 0.00 & 3.66 \\
\hline 8 & $\mathrm{HO}_{2}+\mathrm{H} \rightarrow \mathrm{H}_{2}+\mathrm{O}_{2}$ & $4.276 \mathrm{E}+13$ & 0.00 & 5.9 \\
\hline 9 & $\mathrm{HO}_{2}+\mathrm{H} \rightarrow \mathrm{H}_{2} \mathrm{O}+\mathrm{O}$ & $3.011 \mathrm{E}+13$ & 0.00 & 7.2 \\
\hline 10 & $\mathrm{HO}_{2}+\mathrm{O} \rightarrow \mathrm{OH}+\mathrm{O}_{2}$ & $3.192 \mathrm{E}+13$ & 0.00 & 0 \\
\hline $11 f$ & $\mathrm{HO}_{2}+\mathrm{OH} \rightarrow \mathrm{H}_{2} \mathrm{O}+\mathrm{O}_{2}$ & $2.891 \mathrm{E}+13$ & 0.00 & -2.1 \\
\hline $11 b$ & $\mathrm{O}_{2}+\mathrm{H}_{2} \mathrm{O} \rightarrow \mathrm{OH}+\mathrm{HO}_{2}$ & $3.069 \mathrm{E}+14$ & 0.00 & 300 \\
\hline \multicolumn{5}{|c|}{$0.04 \mathrm{H}_{2} \mathrm{O}_{2}$ Formation/Consumption } \\
\hline 12 & $2 \mathrm{HO}_{2} \rightarrow \mathrm{H}_{2} \mathrm{O}_{2}+\mathrm{O}_{2}$ & $4.215 \mathrm{E}+14$ & 0.00 & 50.1 \\
\hline 13 & $2 \mathrm{HO}_{2} \rightarrow \mathrm{H}_{2} \mathrm{O}_{2}+\mathrm{O}_{2}$ & $1.325 \mathrm{E}+11$ & 0.00 & -6.82 \\
\hline \multirow[t]{2}{*}{$14 \mathrm{f}$} & $2 \mathrm{OH}+\mathrm{M} 2 \rightarrow \mathrm{H}_{2} \mathrm{O}_{2}+\mathrm{M} 2 k_{0}$ & $5.530 \mathrm{E}+19$ & -0.76 & 0 \\
\hline & $k_{\infty}$ & $7.226 \mathrm{E}+13$ & -0.37 & 0 \\
\hline \multirow[t]{2}{*}{$14 b$} & $\mathrm{H}_{2} \mathrm{O}_{2}+\mathrm{M} 2 \rightarrow 2 \mathrm{OH}+\mathrm{M} 2 k_{0}$ & $7.036 \mathrm{E}+21$ & -0.76 & 211 \\
\hline & $k_{\infty}$ & $9.194 \mathrm{E}+15$ & -0.37 & 211 \\
\hline 15 & $\mathrm{H}_{2} \mathrm{O}_{2}+\mathrm{H} \rightarrow \mathrm{H}_{2} \mathrm{O}+\mathrm{OH}$ & $1.024 \mathrm{E}+13$ & 0.00 & 15 \\
\hline $16 \mathrm{f}$ & $\mathrm{H}_{2} \mathrm{O}_{2}+\mathrm{OH} \rightarrow \mathrm{H}_{2} \mathrm{O}+\mathrm{HO}_{2}$ & $7.829 \mathrm{E}+12$ & 0.00 & 5.57 \\
\hline $16 b$ & $\mathrm{HO}_{2}+\mathrm{H}_{2} \mathrm{O} \rightarrow \mathrm{OH}+\mathrm{H}_{2} \mathrm{O}_{2}$ & $1.574 \mathrm{E}+13$ & 0.00 & 131 \\
\hline \multicolumn{5}{|c|}{$1.01 \mathrm{CO}$ Reactions } \\
\hline $17 f$ & $\mathrm{CO}+\mathrm{OH} \rightarrow \mathrm{CO}_{2}+\mathrm{H}$ & $4.400 \mathrm{E}+06$ & 1.50 & -3.1 \\
\hline $17 \mathrm{~b}$ & $\mathrm{H}+\mathrm{CO}_{2} \rightarrow \mathrm{OH}+\mathrm{CO}$ & $1.270 \mathrm{E}+09$ & 1.50 & 98.7 \\
\hline \multicolumn{5}{|c|}{1.03 CHO Reactions } \\
\hline $18 \mathrm{f}$ & $\mathrm{CHO}+\mathrm{M} 2 \rightarrow \mathrm{CO}+\mathrm{H}+\mathrm{M} 2$ & $4.470 \mathrm{E}+14$ & 0.00 & 66 \\
\hline $18 b$ & $\mathrm{CO}+\mathrm{H}+\mathrm{M} 2 \rightarrow \mathrm{CHO}+\mathrm{M} 2$ & $5.490 \mathrm{E}+14$ & 0.00 & 3.07 \\
\hline 19 & $\mathrm{CHO}+\mathrm{H} \rightarrow \mathrm{CO}+\mathrm{H}_{2}$ & $9.033 \mathrm{E}+13$ & 0.00 & 0 \\
\hline 20 & $\mathrm{CHO}+\mathrm{OH} \rightarrow \mathrm{CO}+\mathrm{H}_{2} \mathrm{O}$ & $1.024 \mathrm{E}+14$ & 0.00 & 0 \\
\hline 21 & $\mathrm{CHO}+\mathrm{O}_{2} \rightarrow \mathrm{CO}+\mathrm{HO}_{2}$ & $1.500 \mathrm{E}+12$ & 0.00 & 0 \\
\hline 22 & $\mathrm{CHO}+\mathrm{O}_{2} \rightarrow \mathrm{CO}_{2}+\mathrm{OH}$ & $1.500 \mathrm{E}+12$ & 0.00 & 0 \\
\hline \multicolumn{5}{|c|}{$1.04 \mathrm{CH}_{2} \mathrm{O}$ Reactions } \\
\hline 23 & $\mathrm{CH}_{2} \mathrm{O}+\mathrm{OH} \rightarrow \mathrm{CHO}+\mathrm{H}_{2} \mathrm{O}$ & $3.400 \mathrm{E}+09$ & 1.20 & -1.9 \\
\hline \multicolumn{5}{|c|}{$1.05 \mathrm{CH}_{3}$ Reactions } \\
\hline 24 & $\mathrm{CH}_{3}+\mathrm{O} \rightarrow \mathrm{CH}_{2} \mathrm{O}+\mathrm{H}$ & $8.430 \mathrm{E}+13$ & 0.00 & 0 \\
\hline \multirow[t]{2}{*}{$25 \mathrm{f}$} & $\mathrm{CH}_{3}+\mathrm{H} \rightarrow \mathrm{CH}_{4} \quad k_{0}$ & $6.257 \mathrm{E}+23$ & -1.80 & 0 \\
\hline & $k_{\infty}$ & $2.108 \mathrm{E}+14$ & 0.00 & 0 \\
\hline \multirow[t]{2}{*}{$25 b$} & $\mathrm{CH}_{4} \rightarrow \mathrm{H}+\mathrm{CH}_{3} \quad k_{0}$ & $6.585 \mathrm{E}+25$ & -1.80 & 439 \\
\hline & $k_{\infty}$ & $2.219 \mathrm{E}+16$ & 0.00 & 439 \\
\hline 26 & $\mathrm{CH}_{3}+\mathrm{OH} \rightarrow \mathrm{CH}_{3} \mathrm{O}+\mathrm{H}$ & $5.740 \mathrm{E}+12$ & -0.23 & 58.3 \\
\hline $27 \mathrm{f}$ & $\mathrm{CH}_{3}+\mathrm{OH} \rightarrow \mathrm{CH}_{2} \mathrm{OH}+\mathrm{H}$ & $2.640 \mathrm{E}+19$ & -1.80 & 33.8 \\
\hline $27 \mathrm{~b}$ & $\mathrm{H}+\mathrm{CH}_{2} \mathrm{OH} \rightarrow \mathrm{OH}+\mathrm{CH}_{3}$ & $2.407 \mathrm{E}+20$ & -1.80 & 16.2 \\
\hline 28 & $\mathrm{CH}_{3}+\mathrm{O}_{2} \rightarrow \mathrm{CH}_{2} \mathrm{O}+\mathrm{OH}$ & $3.300 \mathrm{E}+11$ & 0.00 & 37.4 \\
\hline 29 & $\mathrm{CH}_{3}+\mathrm{HO}_{2} \rightarrow \mathrm{CH}_{3} \mathrm{O}+\mathrm{OH}$ & $1.800 \mathrm{E}+13$ & 0.00 & 0 \\
\hline 30 & $\mathrm{CH}_{3}+\mathrm{HO}_{2} \rightarrow \mathrm{CH}_{4}+\mathrm{O}_{2}$ & $3.600 \mathrm{E}+12$ & 0.00 & 0 \\
\hline
\end{tabular}


APPENDIX A

Continued

\begin{tabular}{|c|c|c|c|c|}
\hline \multicolumn{5}{|c|}{$1.06 \mathrm{CH}_{3} \mathrm{O}$ Reactions } \\
\hline \multirow{2}{*}{\multicolumn{5}{|c|}{$1.07 \mathrm{CH}_{2} \mathrm{OH}$ Reactions }} \\
\hline & & & & \\
\hline 32 & $\mathrm{CH}_{2} \mathrm{OH}+\mathrm{M} 2 \rightarrow \mathrm{CH}_{2} \mathrm{O}+\mathrm{H}+\mathrm{M} 2$ & $5.000 \mathrm{E}+13$ & 0.00 & 105 \\
\hline 33 & $\mathrm{CH}_{2} \mathrm{OH}+\mathrm{O}_{2} \rightarrow \mathrm{CH}_{2} \mathrm{O}+\mathrm{HO}_{2}$ & $1.000 \mathrm{E}+13$ & 0.00 & 30 \\
\hline \multicolumn{5}{|c|}{$1.08 \mathrm{CH}_{4}$ Reactions } \\
\hline $34 \mathrm{f}$ & $\mathrm{CH}_{4}+\mathrm{H} \rightarrow \mathrm{H}_{2}+\mathrm{CH}_{3}$ & $1.300 \mathrm{E}+04$ & 3.00 & 33.6 \\
\hline $34 \mathrm{~b}$ & $\mathrm{CH}_{3}+\mathrm{H}_{2} \rightarrow \mathrm{H}+\mathrm{CH}_{4}$ & $4.031 \mathrm{E}+02$ & 3.00 & 29.3 \\
\hline $35 \mathrm{f}$ & $\mathrm{CH}_{4}+\mathrm{O} \rightarrow \mathrm{OH}+\mathrm{CH}_{3}$ & $6.923 \mathrm{E}+08$ & 1.56 & 35.5 \\
\hline $35 \mathrm{~b}$ & $\mathrm{CH}_{3}+\mathrm{OH} \rightarrow \mathrm{O}+\mathrm{CH}_{4}$ & $9.650 \mathrm{E}+06$ & 1.56 & 23.4 \\
\hline $36 \mathrm{f}$ & $\mathrm{CH}_{4}+\mathrm{OH} \rightarrow \mathrm{H}_{2} \mathrm{O}+\mathrm{CH}_{3}$ & $1.600 \mathrm{E}+07$ & 1.83 & 11.6 \\
\hline $36 \mathrm{~b}$ & $\mathrm{CH}_{3}+\mathrm{H}_{2} \mathrm{O} \rightarrow \mathrm{OH}+\mathrm{CH}_{4}$ & $2.309 \mathrm{E}+06$ & 1.83 & 70.8 \\
\hline \multicolumn{5}{|c|}{$1.09 \mathrm{CH}_{3} \mathrm{OH}$ Reactions } \\
\hline \multirow[t]{2}{*}{37} & $\mathrm{OH}+\mathrm{CH}_{3} \rightarrow \mathrm{CH}_{3} \mathrm{OH} k_{0}$ & $1.596 \mathrm{E}+44$ & -8.20 & 0 \\
\hline & $k_{\infty}$ & $6.022 \mathrm{E}+13$ & 0.00 & 0 \\
\hline 38 & $\mathrm{CH}_{3} \mathrm{OH}+\mathrm{H} \rightarrow \mathrm{CH}_{2} \mathrm{OH}+\mathrm{H}_{2}$ & $4.000 \mathrm{E}+13$ & 0.00 & 25.5 \\
\hline 39 & $\mathrm{CH}_{3} \mathrm{OH}+\mathrm{OH} \rightarrow \mathrm{CH}_{2} \mathrm{OH}+\mathrm{H}_{2} \mathrm{O}$ & $1.440 \mathrm{E}+06$ & 2.00 & -3.5 \\
\hline $40 \mathrm{f}$ & $\mathrm{CH}_{3} \mathrm{OH}+\mathrm{OH} \rightarrow \mathrm{CH}_{3} \mathrm{O}+\mathrm{H}_{2} \mathrm{O}$ & $6.300 \mathrm{E}+06$ & 2.00 & 6.28 \\
\hline 40b & $\mathrm{H}_{2} \mathrm{O}+\mathrm{CH}_{3} \mathrm{O} \rightarrow \mathrm{OH}+\mathrm{CH}_{3} \mathrm{OH}$ & $1.598 \mathrm{E}+07$ & 2.00 & 70.3 \\
\hline
\end{tabular}

Units are mol, cubic centimeters, seconds, kJoules, Kelvin.

Third body collision efficiencies are

$[\mathrm{M0}]=1.0\left[\mathrm{H}_{2}\right]+1.0\left[\mathrm{~N}_{2}\right]+6.4\left[\mathrm{H}_{2} \mathrm{O}\right]+0.4\left[\mathrm{O}_{2}\right]+1.0[$ OTHERS $]$

$[\mathrm{M} 1]=0.6\left[\mathrm{H}_{2}\right]+0.4\left[\mathrm{~N}_{2}\right]+0.44\left[\mathrm{H}_{2} \mathrm{O}\right]+0.4\left[\mathrm{O}_{2}\right]+1.5\left[\mathrm{CO}_{2}\right]+3.0\left[\mathrm{CH}_{4}\right]+1.0$ [OTHERS $]$

$[\mathrm{M} 2]=1.0\left[\mathrm{H}_{2}\right]+0.4\left[\mathrm{~N}_{2}\right]+6.5\left[\mathrm{H}_{2} \mathrm{O}\right]+0.4\left[\mathrm{O}_{2}\right]+1.0[$ OTHERS $]$

For those rate constants $k$, which depend on the pressure, $k_{0}$ and $k_{\infty}$ are given in the table and $k=F k_{0} k_{\infty}[\mathrm{M}] /$ $\left(k_{\infty}+k_{0}[\mathrm{M}]\right)$, where $\log _{10} F=\log _{10} F_{c} /\left(1+\left(\log _{10}\left(k_{0}[\mathrm{M}] / k_{\infty}\right) / N\right)^{2}\right)$ and $\hat{N}=0.75-1.27 \log _{10} F_{c}$.

Broadening functions are:

$F_{c 14}=0.5$

$F_{c 25}=0.577 \exp (-T / 2370)$

$F_{c 37}=0.18 \exp (-T / 200)+0.82 \exp (-T / 1438)$ 


\section{APPENDIX B}

$\mathrm{NO}_{x}$ Mechanism

\begin{tabular}{|c|c|c|c|c|}
\hline Number & Reaction & $A$ & $n$ & $E$ \\
\hline \multicolumn{5}{|c|}{ N.02 $\mathrm{NH}_{2}$ Consumption } \\
\hline N1 & $\mathrm{NH}_{2}+\mathrm{O} \rightarrow \mathrm{HNO}+\mathrm{H}$ & $4.500 \mathrm{E}+13$ & 0.00 & 0 \\
\hline $\mathrm{N} 2 \mathrm{f}$ & $\mathrm{NH}_{2}+\mathrm{OH} \rightarrow \mathrm{NH}+\mathrm{H}_{2} \mathrm{O}$ & $4.000 \mathrm{E}+06$ & 2.00 & 4.19 \\
\hline $\mathrm{N} 2 \mathrm{~b}$ & $\mathrm{H}_{2} \mathrm{O}+\mathrm{NH} \rightarrow \mathrm{OH}+\mathrm{NH}_{2}$ & $1.296 \mathrm{E}+07$ & 2.00 & 121 \\
\hline N3f & $\mathrm{NH}_{2}+\mathrm{NO} \rightarrow \mathrm{N}_{2} \mathrm{H}+\mathrm{OH}$ & $9.300 \mathrm{E}+11$ & 0.00 & 0 \\
\hline $\mathrm{N} 3 \mathrm{~b}$ & $\mathrm{OH}+\mathrm{N}_{2} \mathrm{H} \rightarrow \mathrm{NO}+\mathrm{NH}_{2}$ & $5.946 \mathrm{E}+11$ & 0.00 & 5.31 \\
\hline \multicolumn{5}{|c|}{ N.03 NH Consumption } \\
\hline N4 & $\mathrm{NH}+\mathrm{O} \rightarrow \mathrm{NO}+\mathrm{H}$ & $5.500 \mathrm{E}+13$ & 0.00 & 0 \\
\hline N5 & $\mathrm{NH}+\mathrm{O} \rightarrow \mathrm{N}+\mathrm{OH}$ & $3.720 \mathrm{E}+13$ & 0.00 & 0 \\
\hline N6 & $\mathrm{NH}+\mathrm{OH} \rightarrow \mathrm{N}+\mathrm{H}_{2} \mathrm{O}$ & $2.000 \mathrm{E}+09$ & 1.20 & 0.03 \\
\hline N7 & $\mathrm{NH}+\mathrm{OH} \rightarrow \mathrm{HNO}+\mathrm{H}$ & $2.000 \mathrm{E}+13$ & 0.00 & 0 \\
\hline N8f & $\mathrm{NH}+\mathrm{OH} \rightarrow \mathrm{NH}_{2}+\mathrm{O}$ & $9.990 \mathrm{E}+11$ & 0.10 & 48.2 \\
\hline $\mathrm{N} 8 \mathrm{~b}$ & $\mathrm{O}+\mathrm{NH}_{2} \rightarrow \mathrm{OH}+\mathrm{NH}$ & $3.193 \mathrm{E}+12$ & 0.10 & 3.1 \\
\hline N9 & $\mathrm{NH}+\mathrm{O}_{2} \rightarrow \mathrm{HNO}+\mathrm{O}$ & $3.914 \mathrm{E}+13$ & 0.00 & 74.8 \\
\hline N10 & $\mathrm{NH}+\mathrm{O}_{2} \rightarrow \mathrm{NO}+\mathrm{OH}$ & $4.500 \mathrm{E}+08$ & 0.79 & 5 \\
\hline N11f & $\mathrm{NH}+\mathrm{NO} \rightarrow \mathrm{N}_{2} \mathrm{O}+\mathrm{H}$ & $3.140 \mathrm{E}+14$ & -0.45 & 0 \\
\hline N11b & $\mathrm{H}+\mathrm{N}_{2} \mathrm{O} \rightarrow \mathrm{NO}+\mathrm{NH}$ & $1.455 \mathrm{E}+17$ & -0.45 & 146 \\
\hline $\mathrm{N} 12 \mathrm{f}$ & $\mathrm{NH}+\mathrm{NO} \rightarrow \mathrm{N}_{2}+\mathrm{OH}$ & $2.200 \mathrm{E}+13$ & -0.23 & 0 \\
\hline $\mathrm{N} 12 \mathrm{~b}$ & $\mathrm{OH}+\mathrm{N}_{2} \rightarrow \mathrm{NO}+\mathrm{NH}$ & $1.834 \mathrm{E}+14$ & -0.23 & 409 \\
\hline \multicolumn{5}{|c|}{ N.04 HNO Consumption } \\
\hline N13f & $\mathrm{HNO}+\mathrm{M} \rightarrow \mathrm{H}+\mathrm{NO}+\mathrm{M}$ & $1.500 \mathrm{E}+16$ & 0.00 & 204 \\
\hline $\mathrm{N} 13 \mathrm{~b}$ & $\mathrm{NO}+\mathrm{H}+\mathrm{M} \rightarrow \mathrm{HNO}+\mathrm{M}$ & $2.238 \mathrm{E}+15$ & 0.00 & 2.22 \\
\hline N14 & $\mathrm{HNO}+\mathrm{H} \rightarrow \mathrm{NO}+\mathrm{H}_{2}$ & $4.400 \mathrm{E}+11$ & 0.72 & 2.72 \\
\hline $\mathrm{N} 15 \mathrm{f}$ & $\mathrm{HNO}+\mathrm{OH} \rightarrow \mathrm{NO}+\overrightarrow{\mathrm{H}}_{2} \mathrm{O}$ & $3.600 \mathrm{E}+13$ & 0.00 & 0 \\
\hline $\mathrm{N} 15 \mathrm{~b}$ & $\mathrm{H}_{2} \mathrm{O}+\mathrm{NO} \rightarrow \mathrm{OH}+\mathrm{HNO}$ & $8.158 \mathrm{E}+13$ & 0.00 & 296 \\
\hline \multicolumn{5}{|c|}{ N.06 N Consumption } \\
\hline N16f & $\mathrm{N}+\mathrm{O}_{2} \rightarrow \mathrm{NO}+\mathrm{O}$ & $9.033 \mathrm{E}+09$ & 1.00 & 27.2 \\
\hline $\mathrm{N} 16 \mathrm{~b}$ & $\mathrm{O}+\mathrm{NO} \rightarrow \mathrm{O}_{2}+\mathrm{N}$ & $1.804 \mathrm{E}+09$ & 1.00 & 159 \\
\hline N17f & $\mathrm{N}+\mathrm{OH} \rightarrow \mathrm{NO}+\mathrm{H}$ & $2.830 \mathrm{E}+13$ & 0.00 & 0 \\
\hline $\mathrm{N} 17 \mathrm{~b}$ & $\mathrm{H}+\mathrm{NO} \rightarrow \mathrm{OH}+\mathrm{N}$ & $9.758 \mathrm{E}+13$ & 0.00 & 202 \\
\hline N18f & $\mathrm{N}+\mathrm{NO} \rightarrow \mathrm{N}_{2}+\mathrm{O}$ & $4.276 \mathrm{E}+13$ & 0.00 & 6.57 \\
\hline $\mathrm{N} 18 \mathrm{~b}$ & $\mathrm{O}+\mathrm{N}_{2} \rightarrow \mathrm{NO}+\mathrm{N}$ & $1.809 \mathrm{E}+14$ & 0.00 & 321 \\
\hline \multicolumn{5}{|c|}{ N.07 $\mathrm{N}_{2} \mathrm{H}$ Consumption } \\
\hline N19f & $\mathrm{N}_{2} \mathrm{H} \rightarrow \mathrm{N}_{2}+\mathrm{H}$ & $1.000 \mathrm{E}+08$ & 0.00 & 0 \\
\hline $\mathrm{N} 19 \mathrm{~b}$ & $\mathrm{H}+\mathrm{N}_{2} \rightarrow \mathrm{N}_{2} \mathrm{H}$ & $2.780 \mathrm{E}+08$ & 0.00 & 22.3 \\
\hline $\mathrm{N} 20$ & $\mathrm{~N}_{2} \mathrm{H}+\mathrm{H} \rightarrow \mathrm{N}_{2}+\mathrm{H}_{2}$ & $1.000 \mathrm{E}+14$ & 0.00 & 0 \\
\hline $\mathrm{N} 21 \mathrm{f}$ & $\mathrm{N}_{2} \mathrm{H}+\mathrm{O} \rightarrow \mathrm{N}_{2} \mathrm{O}+\mathrm{H}$ & $1.400 \mathrm{E}+14$ & -0.40 & 2 \\
\hline $\mathrm{N} 21 \mathrm{~b}$ & $\mathrm{~N}_{2} \mathrm{O}+\mathrm{H} \rightarrow \mathrm{N}_{2} \mathrm{H}+\mathrm{O}$ & $5.500 \mathrm{E}+18$ & -1.06 & 198 \\
\hline $\mathrm{N} 22$ & $\mathrm{~N}_{2} \mathrm{H}+\mathrm{OH} \rightarrow \mathrm{N}_{2}+\mathrm{H}_{2} \mathrm{O}$ & $5.000 \mathrm{E}+13$ & 0.00 & 0 \\
\hline \multicolumn{5}{|c|}{ N.08 $\mathrm{N}_{2} \mathrm{O}$ Consumption } \\
\hline \multirow[t]{2}{*}{ N23f } & $\mathrm{N}_{2} \mathrm{O} \rightarrow \mathrm{N}_{2}+\mathrm{O} \quad k_{0}$ & $9.000 \mathrm{E}+14$ & 0.00 & 237 \\
\hline & $k_{\infty}$ & $1.260 \mathrm{E}+12$ & 0.00 & 262 \\
\hline \multirow[t]{2}{*}{$\mathrm{N} 23 \mathrm{~b}$} & $\mathrm{O}+\mathrm{N}_{2} \rightarrow \mathrm{N}_{2} \mathrm{O} \quad k_{0}$ & $1.103 \mathrm{E}+13$ & 0.00 & 73.4 \\
\hline & $k_{\infty}$ & $1.545 \mathrm{E}+10$ & 0.00 & 98.4 \\
\hline $\mathrm{N} 24 \mathrm{f}$ & $\mathrm{N}_{2} \mathrm{O}+\mathrm{H} \rightarrow \mathrm{N}_{2}+\mathrm{OH}$ & $2.230 \mathrm{E}+14$ & 0.00 & 70.1 \\
\hline $\mathrm{N} 24 \mathrm{~b}$ & $\mathrm{OH}+\mathrm{N}_{2} \rightarrow \mathrm{H}+\mathrm{N}_{2} \mathrm{O}$ & $4.011 \mathrm{E}+12$ & 0.00 & 333 \\
\hline N25 & $\mathrm{N}_{2} \mathrm{O}+\mathrm{O} \rightarrow 2 \mathrm{NO}$ & $6.620 \mathrm{E}+13$ & 0.00 & 111 \\
\hline N26 & $\mathrm{N}_{2} \mathrm{O}+\mathrm{O} \rightarrow \mathrm{N}_{2}+\mathrm{O}_{2}$ & $1.020 \mathrm{E}+14$ & 0.00 & 117 \\
\hline \multicolumn{5}{|c|}{ N.09 $\mathrm{NO}_{2}$ Formation and Consumption } \\
\hline $\mathrm{N} 27 \mathrm{f}$ & $\mathrm{NO}+\mathrm{O}+\mathrm{M} \rightarrow \mathrm{NO}_{2}+\mathrm{M}$ & $4.700 \mathrm{E}+24$ & -2.87 & 6.5 \\
\hline $\mathrm{N} 27 \mathrm{~b}$ & $\mathrm{NO}_{2}+\mathrm{M} \rightarrow \mathrm{O}+\mathrm{NO}+\mathrm{M}$ & $4.888 \mathrm{E}+26$ & -2.87 & 310 \\
\hline N28f & $\mathrm{NO}+\mathrm{HO}_{2} \rightarrow \mathrm{NO}_{2}+\mathrm{OH}$ & $2.110 \mathrm{E}+12$ & 0.00 & -2 \\
\hline $\mathrm{N} 28 \mathrm{~b}$ & $\mathrm{OH}+\mathrm{NO}_{2} \rightarrow \mathrm{HO}_{2}+\mathrm{NO}$ & $8.881 E+12$ & 0.00 & 36.1 \\
\hline $\mathrm{N} 29 \mathrm{f}$ & $\mathrm{NO}_{2}+\mathrm{H} \rightarrow \mathrm{NO}+\mathrm{OH}$ & $3.500 \mathrm{E}+14$ & 0.00 & 6.28 \\
\hline $\mathrm{N} 29 \mathrm{~b}$ & $\mathrm{OH}+\mathrm{NO} \rightarrow \mathrm{H}+\mathrm{NO}_{2}$ & $4.938 \mathrm{E}+12$ & 0.00 & 130 \\
\hline
\end{tabular}

Units are mol, cubic centimeters, seconds, kJoules, Kelvin.

The reaction-rate constants $k_{23 f}$ and $k_{23 b}$ are given in terms of the constants $k_{0}$ and $k_{\infty}$ given in the table by $k=$ $k_{0} k_{\infty}[\mathrm{M}] /\left(k_{\infty}+k_{0}[\mathrm{M}]\right)$. 